PONTIFÍCIA UNIVERSIDADE CATÓLICA DO RIO DE JANEIRO

\title{
Valuation de uma Líder de Capital Aberto do setor de Mídia Mundial - Netflix
}

\author{
Juliana Nabuco de Magalhães Lins Villaça
} Renault

Trabalho de Conclusão de Curso

Centro de CIÊnCIAS SOCIAIS - CCS

DEPARTAMENTO de ADMINISTRAÇÃo

Graduação em Administração de Empresas 
Juliana Nabuco de Magalhães Lins Villaça Renault

\section{Valuation de uma Líder de Capital Aberto do Setor de Mídia Mundial - Netflix}

Trabalho de Conclusão de Curso

Trabalho de Conclusão de Curso, apresentado ao programa de graduação em Administração da PUC-Rio como requisito parcial para a obtenção do título de graduação em Administração.

Orientador: Luiz Brandão

Rio de Janeiro

junho de 2019. 


\section{Resumo}

Renault, Juliana Nabuco de Magalhães Lins Villaça Renault. Valuation de uma Líder de Capital Aberto do Setor de Mídia Mundial - Netflix. Rio de Janeiro, 2019. 48 p. Trabalho de Conclusão de Curso - Departamento de Administração. Pontifícia Universidade Católica do Rio de Janeiro.

Este trabalho busca determinar o valor da Netflix a fim de verificar se a mesma está precificada acima ou abaixo do seu valor de mercado. Para tanto, foram utilizados os métodos de valuation baseado em seus usuários e a análise relativa por múltiplos. Além disso, buscou-se analisar também os fatores externos e internos à organização, como seu modelo de negócio e o mercado de streaming, com a intenção de projetar resultados futuros. Os resultados indicam que apesar da empresa conseguir crescer a dígitos duplos, agregar um valor relativamente alto com novos usuários, e ter custos corporativos controlados, a Netflix encontrase supervalorizada no mercado. Assim, conclui-se que a empresa esta precificada abaixo do seu valor de mercado, o que não recomenda a compra.

Palavras-chave: Avaliação de empresas, Streaming, Entretenimento, Mercado.

\section{Abstract}

Renault, Juliana Nabuco de Magalhães Lins Villaça Renault. Valuation of a World Leader of the Media Sector - Netflix. Rio de Janeiro, 2019. 48 p. Trabalho de Conclusão de Curso - Departamento de Administração. Pontifícia Universidade Católica do Rio de Janeiro.

This work seeks to determine the value of Netflix in order to verify if it is over or undervalued by the market. Two valuation models were used: a subscriptionbased approach and a relative valuation based on multiples. In addition, the external and internal factors of the organization were also analyzed such as its business model, the streaming industry and main players, with the intention of projecting future results. The results indicate that even though the company manages to grow at double-digit rates, adds a relatively high value with new users and has corporate costs under control, Netflix finds itself overvalued in the market. Therefore, its stock doesn't have a buy recommendation.

Key-words: Valuation, Streaming, Entertainment, Market. 


\section{Sumário}

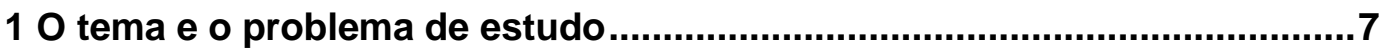

1.1. Introdução ao tema e ao problema de estudo........................................

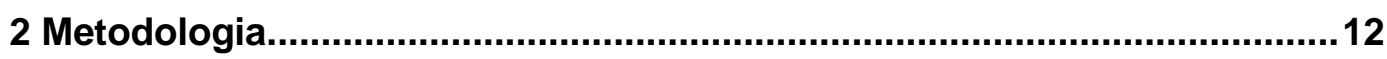

2.1. Valuation baseado no valor do usuário: subscription - based approach.. 12

2.1.1. Custo médio ponderado de capital (WACC) …................................ 13

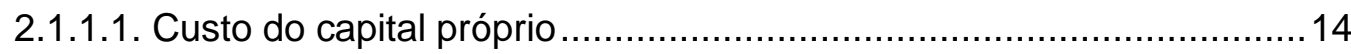

2.1.1.2. Custo de capital de terceiros ............................................... 15

2.1.1.3. Avaliação Relativa ............................................................. 16

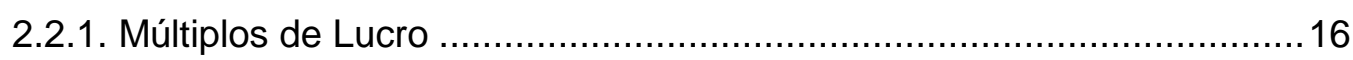

2.2.1.1. Preço por ação / Lucro por ação (P/L) ......................................... 16

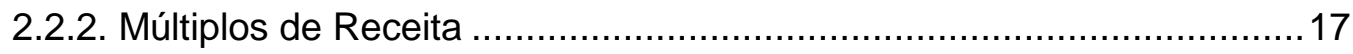

2.2.2.1. Preço / Receita (P/S) ........................................................ 17

2.2.2.2. Valor da empresa/ Receitas (EV/S) ......................................... 17

2.2.3. Múltiplos de patrimônio ............................................................. 18

2.2.3.1. Preço / Patrimônio Líquido (P/PL) .............................................. 18

2.2.4. Múltiplos de EBITDA............................................................... 18

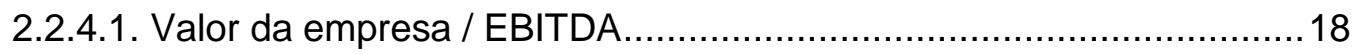

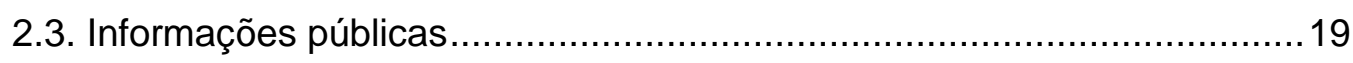

30 mercado de streaming ....................................................................20

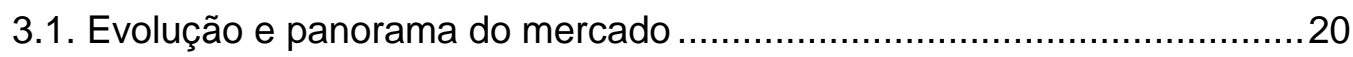

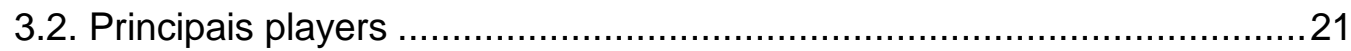

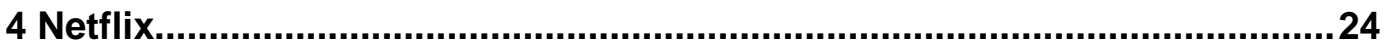

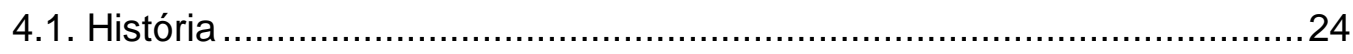

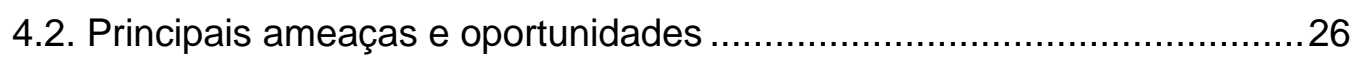

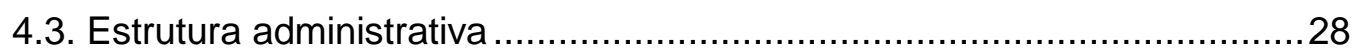

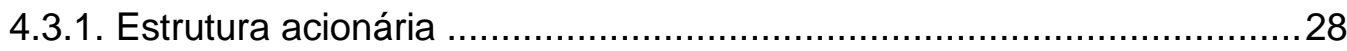




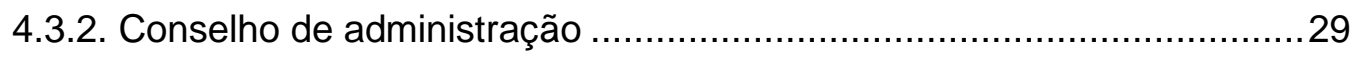

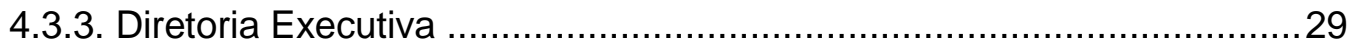

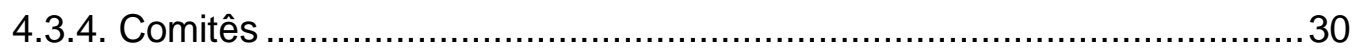

4.3.4.1. Comitê de Remuneração ............................................................30

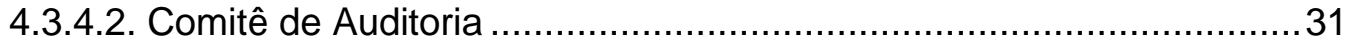

4.3.4.3. Comitê de Governança e Indicação................................................ 31

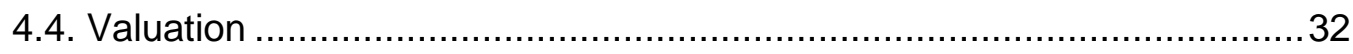

4.4.1. Valuation baseado no valor do usuário: subscription-based approach..32

4.4.1.1. Custo Médio de Capital Ponderado (WACC) ..................................33

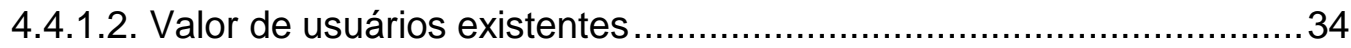

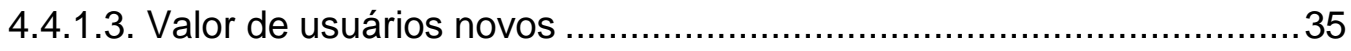

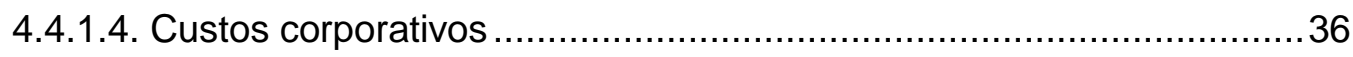

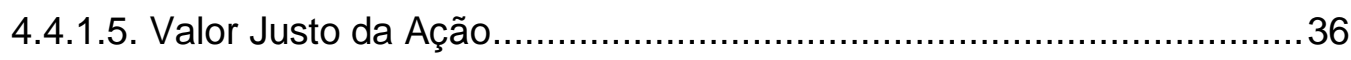

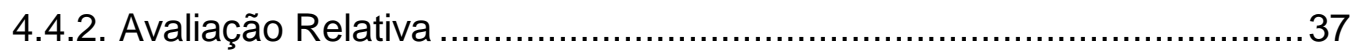

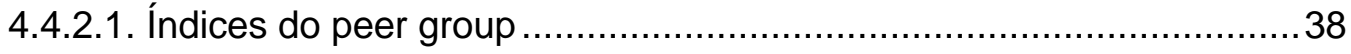

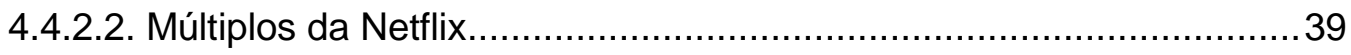

4.4.2.2.1. Múltiplos de Lucro........................................................... 40

4.4.2.2.2. Múltiplos de Receita ...................................................... 41

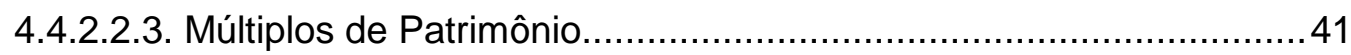

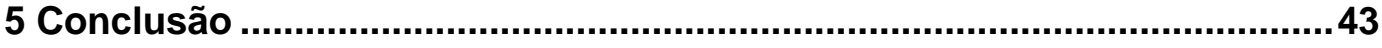

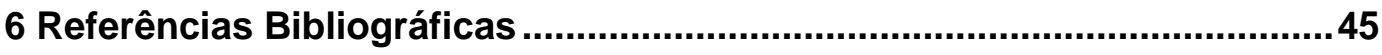

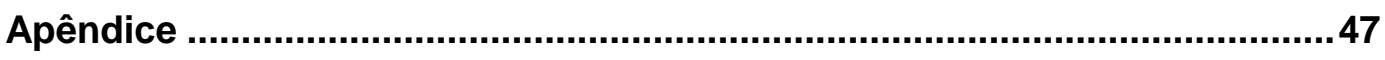

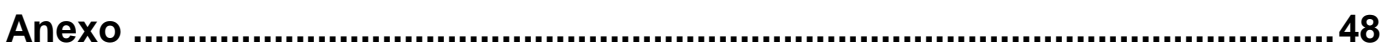




\section{Lista de figuras}

Figura 1: Crescimento internacional da Netflix $\quad 8$

Figura 2: Evolução do fluxo de caixa da Netflix por trimestre 9

Figura 3: Fatores que influenciam o corte de serviço de satélite/ a cabo 20

Figura 4: Usuários globais do serviço de Streaming de vídeo 21

Figura 5: Valorização da Netflix (jan/2009 até fev/2019) 25

Figura 6: Preço cobrado pelo serviço em diferentes regiões 25

Figura 7: Evolução do múltiplo de lucro $\quad 40$

Figura 8: Evolução dos múltiplos de receita 41

Figura 9: Evolução do Múltiplo de Patrimônio Líquido 42

Figura 10: Evolução do múltiplo de EBITDA 42

\section{Lista de Tabelas}

Tabela 1: Plataformas de streaming: preço e market share 23

Tabela 2: Evolução da dívida de longo-prazo 28

Tabela 3: Estrutura acionária por Tipo de Investidor e Tipo de Acionista 28

Tabela 4: Formação do Conselho de administração 29

$\begin{array}{ll}\text { Tabela 5: Diretoria Executiva } & 29\end{array}$

Tabela 6: Membros do Comitê de Remuneração 30

Tabela 7: Membros do comitê de Auditoria 31

Tabela 8: Membros do comitê de Governança e Indicação 31

Tabela 9: Premissas adotadas para o valuation 33

Tabela 10: Variáveis para o cálculo do custo de capital 33

$\begin{array}{ll}\text { Tabela 11: WACC da Netflix } & 34\end{array}$

Tabela 12: Valor de usuários existentes $\quad 34$

Tabela 13: Lucro de usuários novos no ano corrente 35 
Tabela 14: Valor adicionado por novos usuários

Tabela 15: Custos corporativos 36

Tabela 16: Calculando o preço justo por ação da Netflix 37

Tabela 17: Análise comparativa da Netflix e de peers do ano de $2018 \quad 38$

Tabela 18: Múltiplos da Netflix de 2015 a 2018 


\section{0 tema e o problema de estudo}

Este capítulo tem como objetivo apresentar o tema a ser desenvolvido e o problema de estudo.

Desse modo, é realizado uma contextualização do assunto, introduzindo o tema, o problema que suscitou a investigação e os objetivos do estudo. Em seguida são apresentados o foco e delimitação e por fim a relevância do estudo.

\subsection{Introdução ao tema e ao problema de estudo}

A Netflix revolucionou o mercado de entretenimento: pioneira e líder do serviço de streaming ${ }^{1}$, a empresa conseguiu mudar radicalmente as preferências do consumidor. Em 2007 a empresa lançou pela primeira vez seu serviço de streaming, que com a proliferação da internet tornou possível assistir a uma gama de conteúdo de casa, sem a necessidade de ir a uma locadora. Em 2010 começou a expansão para níveis internacionais, e a empresa foi vista muito mais que o futuro de aluguel de filmes, e sim como uma tecnologia disruptiva que estaria mudando drasticamente o mercado de entretenimento.

Em termos de usuários, expansão internacional e fatia de mercado, a Netflix é hoje a empresa com maior sucesso nesse segmento. Presente em mais de 190 países, até o primeiro trimestre de 2019 a empresa conta com mais de 158 milhões de usuários: 39\% norte americanos, e 61\% internacionais. Mais um dado impressionante: em 2017, 37\% dos usuários globais de internet eram também assinantes da Netflix. (Statista, 2019).

\footnotetext{
${ }^{1}$ Streaming pode ser definida como um meio de transmissão de multimídia, que usa especialmente a internet para transferência de dados.
} 
Figura 1 - Crescimento internacional da Netflix.

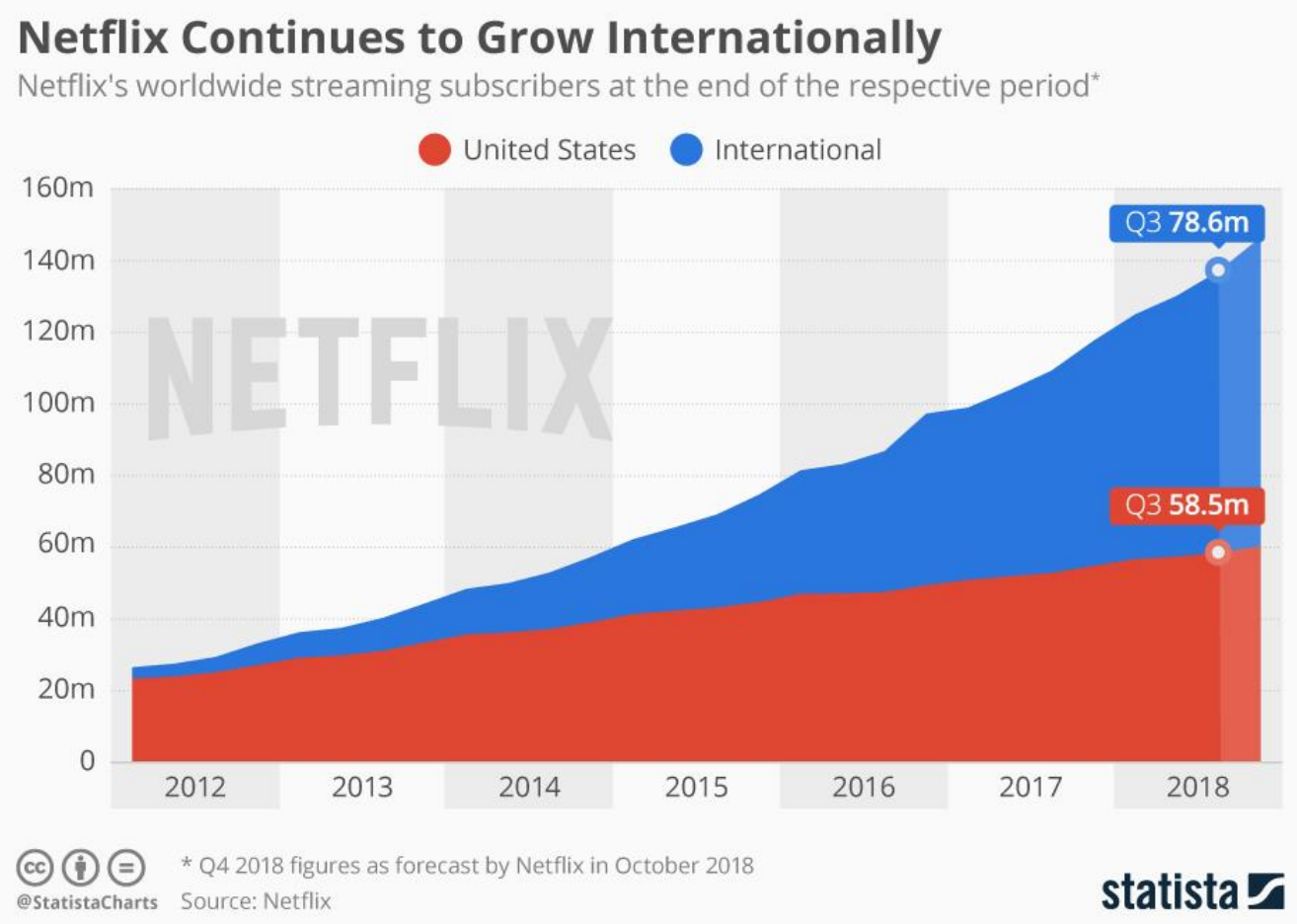

Fonte: Statista, 2018.

Por outro lado, ao olhar o preço das suas ações, as principais preocupações relacionadas a empresa não parecem estar nelas refletidas: o fluxo de caixa da empresa vem sendo cada vez mais negativo, assim como a dívida líquida; a empresa vem encarando dificuldade de penetração em mercados emergentes, especialmente na Índia; há muitos novos players no mercado, tornando esse setor muito mais competitivo. Nos trimestres recentes, o que parece ditar a reação do mercado é o aumento da base de usuários do período, ao invés de qualquer métrica relacionada a performance financeira e o surgimento de diversos competidores. 
Figura 2 - Evolução do fluxo de caixa da Netflix por trimestre.

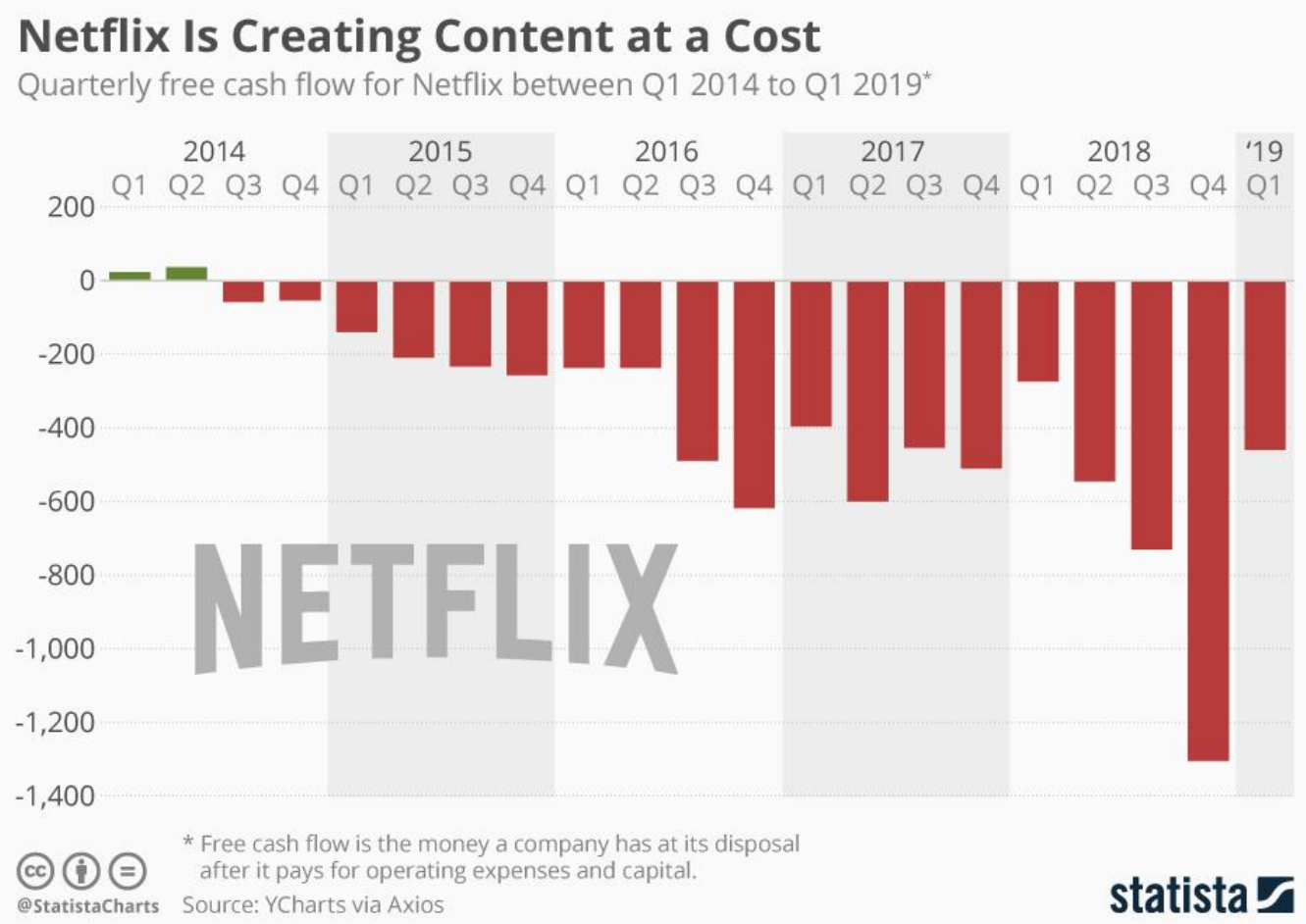

Fonte: Statista, 2019.

Até o momento, o mercado ainda acredita no potencial da empresa e que ela pode continuar crescendo e se mantendo nesses níveis, pagando um múltiplo muito alto por uma empresa que gera fluxos de caixa negativos. Apenas para manter coisas em perspectivas ao discutir valuation, consideremos o seguinte:

De setembro 2017 a setembro 2018, a Netflix faturou USD 15 bilhões, lucrou USD 1.3 Bilhões e gerou USD 2.1 Bilhões de fluxo de caixa livre negativo. Já a Disney faturou USD 58 Bilhões, lucrou USD 10.1 Bilhões e gerou USD 9.7 Bilhões de fluxo de caixa (positivo). A Netflix, na data do recolhimento desses dados ${ }^{2}$, tinha uma capitalização de mercado de USD 156 Bilhões enquanto a Disney era de USD 174 Bilhões (Bloomberg, novembro 2018).

Investidores defendem a Netflix com o discurso de que eles podem mais que dobrar sua base de usuários, e uma vez que isso aconteça, sua dívida já vai ter sido paga por si só. Mas como já mencionado, eles atingiram a marca de 158 milhões de usuários ao redor do mundo e devido à dificuldade de expandir para mercados

\footnotetext{
${ }^{2}$ Dados de 22 de outubro de 2018.
} 
promissores, estão concentrando seus esforços para adaptar o catalogo e conteúdo original para cada região a fim de aumentar sua base - e há algum outro jeito de fazer isso senão deixando seu fluxo de caixa ainda mais negativo? Sem contar que com o surgimento de novos players, a tendência é que eles sejam de nicho, oferecendo conteúdo que agrade mais o público culturalmente, e que seja mais condizente com o preço de que cada população possa pagar.

\subsection{Objetivo do estudo}

Este trabalho se propõe a realizar o valuation da Netflix, uma empresa de capital aberto do setor de mídia listada na bolsa de valores norte-americana, a fim de determinar qual seria seu valor justo de mercado.

\subsection{Objetivos intermediários do estudo}

Para determinar precificação de mercado da empresa, o primeiro item a ser analisado será o macro ambiente. O enfoque maior será nos competidores, entrada de novos players, tendências de mercado e um estudo da famosa e tão concorrida "streaming war", demonstrando entender as forças externas que atuam no segmento.

Em segundo lugar, será realizada uma análise do modelo de negócios da empresa, com foco na sustentabilidade do business.

A análise financeira também será realizada, levando em conta o fluxo de caixa descontado, fora uma valuation comparativa levando em conta os principais indicadores financeiros: múltiplos de Lucro, de receita, de Patrimônio Líquido e de EBITDA.

Como forma de complemento serão estudadas também as estratégias para expansão e crescimento da empresa, como pressupostos para definir o valor justo da ação. 


\subsection{Delimitação e o foco do estudo}

Este estudo volta-se mais especificamente para realizar a avaliação de preço da Netflix, e para chegar a conclusão se ela realmente vale o preço que está precificada hoje. Embora relevante, não pretende tratar das disrupções e mudanças que a empresa causou no setor de mídia, e como ela mudou as preferências e experiências do telespectador.

O estudo não levará em conta - também de extrema importância - as pessoas que comandam a empresa: quem está no Conselho, quem é o CEO, e outros cargos de alto escalão, que influenciam significantemente sua estratégia. Será um trabalho voltado para análise de resultados e do ambiente externo.

\subsection{Justificativa e relevância}

As informações desse estudo podem ser de interesse para empresas de mídia, pois a valuation pelo método comparativo inclui dados de players do setor, fora a análise do ambiente externo que será realizada, disponibilizando dados e opiniões. Tais informações também podem servir para investidores que, ao comprar ações da Netflix, podem acabar não levando em consideração métricas financeiras fundamentais, focando no aumento de usuários.

Por fim, torna-se importante para empresas e gestores em geral, pois reflete que mesmo uma gigante como a Netflix, que causou uma disrupção no mercado e mudou preferências dos consumidores, pode ter problemas e dificuldades financeiras. Mostra mais uma vez a importância de uma boa gestão financeira e estratégias bem definidas para estar sempre a frente na corrida empresarial. 


\section{Referencial Teórico}

Este capítulo abordará aspectos conceituais e teóricos, apresentando estudos e referências bibliográficas relacionados ao tema em estudo, que servirão de base para a valuation da Netflix.

Esta seção será dividida em três partes: avaliação por fluxo de caixa descontado, avaliação por múltiplos e informações públicas disponibilizadas pela empresa em estudo.

\subsection{Valuation baseado no valor do usuário: subscription - based approach}

Este método de valuation estima o valor de um investimento baseado no valor tanto de usuários já existentes como também de novos usuários. O modelo desconta o custo que cada um deles gera para empresa, assim como os custos que a empresa incorrerá independente deles.

Esse modelo foi criado pelo Professor Aswath Damodaran ${ }^{3}$, ao realizar a valuation da Spotify $^{4}$. Foi optado essa forma de avaliação por dois motivos principais:

1. O fluxo de caixa da Netflix é negativo. A abordagem de fluxo de caixa descontado só deve ser usada quando a empresa possuir fluxo de caixa positivo no ano terminal e quando a soma dos fluxos de caixa for positiva. (Damodaran, 2012).

\footnotetext{
${ }^{3}$ Damodaran é Professor de finanças corporativas e valuation da Stern School of Business, na Universidade de Nova Iorque (NYU). É mais conhecido como autor de diversos textos acadêmicos, e muito bem reconhecido pelo mercado.

${ }^{4}$ Serviço de streaming de música, podcast e vídeo, lançado em 2008 e que já tem uma presença global. A empresa já conta com mais de 170 milhões de usuários.
} 
2. Por ser uma empresa que oferece serviço de streaming, a Spotify se assemelha ao modelo da Netflix e, portanto, podem ser comparáveis nesse aspecto.

A abordagem baseada em usuários é dividida em três partes principais. Primeiro, determina-se o valor de usuários já existente com base em resultados divulgados pela empresa. A partir disso, é realizada uma projeção do que a empresa poderá produzir no futuro. Em seguida, determina-se o valor de potenciais novos usuários, chegando a um valor terminal. A terceira parte inclui realizar um desdobramento de custos corporativos, que são aqueles que não podem ser diretamente relacionados ao usuário, como por exemplo custos com tecnologia e desenvolvimento. Todas as projeções são trazidas a valor presente usando uma taxa de desconto, composta por todos os custos de capital e pelos riscos de investimento. Com essas três partes concluídas, torna-se possível chegar no preço justo por ação da empresa.

\subsubsection{Custo médio ponderado de capital (WACC)}

Como indica o nome, o custo médio ponderado de capital é a média do custo de capital próprio e de terceiros, levando em conta a porcentagem que cada uma dessas entradas representa da empresa. O WACC pode ser considerado a taxa de juros que as empresas usam para descontar o valor do dinheiro no tempo.

Desse modo, essa taxa mede tanto a remuneração requerida sobre o capital investido quanto o custo de oportunidade dos investidores no negócio, podendo ser utilizada como uma taxa de desconto sob as projeções futuras.

$$
\mathrm{VPL}: \sum_{t=1}^{T} \frac{F C F F}{(1+W A C C)^{\wedge} t}
$$

O WACC é o retorno exigido sobre o capital investido para a empresa atingir o equilíbrio. Ou seja, é a taxa mínima que a empresa ou ativo deva oferecer para que seu investimento seja atraente. 


$$
\text { WACC }=K e * \frac{E}{E+D}+K d *(1-T) * \frac{D}{D+E}
$$

Onde:

$\mathrm{Ke}=$ Custo do capital próprio

$\mathrm{E}=$ Participação do capital próprio

$\mathrm{D}=$ Participação do capital de terceiros

$\mathrm{Kd}=$ Custo do capital de terceiros (Despesa com juros / Dívida total)

$\mathrm{T}=$ Alíquota de imposto de renda

\subsubsection{Custo do capital próprio}

O custo de capital próprio é dado pelo retorno esperado sobre o Patrimônio Líquido durante um determinado período de tempo baseado na taxa de juros do mercado.

Segundo Damodaran (1997) e Ross (2013), a taxa de desconto para trazer projeções futuras para valor presente pode ser calculada de duas maneiras: pelo modelo de custo de capital próprio (CAPM), e pelo modelo de crescimento de dívidendos.

$$
\mathrm{VPL}=\sum_{t=1}^{\infty} \frac{F C F E t}{(1+K e)^{\wedge} t}
$$

O CAPM foi desenvolvido em 1964 por William Sharpe, e é o modelo mais utilizado para obtenção do custo do capital próprio. Ele descreve a relação risco retorno ao investir num determinado ativo, mostrando que o retorno esperado de um ativo é igual ao retorno de um investimento sem risco (que rende a taxa básica de juros), acrescido por um prêmio de risco, medido pelo beta.

$$
\mathrm{CAPM}=\frac{\{[R f+\beta *(R m-R f)+R c+R e]+1\}}{1+C P I}
$$


Onde:

$\mathrm{Rf}=$ Taxa livre de risco

$\beta=$ Risco sistemático (não diversificável)

$\mathrm{Rm}=$ Retorno de mercado

$\mathrm{Rm}-\mathrm{Rf}=$ Prêmio de risco do mercado

$\mathrm{Rc}=$ Risco país

$\operatorname{Re}=$ Risco cambial

Já o modelo de crescimento de dividendos, por mais que seja mais fácil de ser implementado, requer que a empresa esteja passando por momento de estabilidade, ou seja, nem crescendo nem decrescendo. Isso impõe uma forte restrição a esse modelo, e segundo Ross (2013), “é difícil dizer se o retorno estimado é compatível ou não com o nível de risco existente”.

$$
R=\frac{D_{1}}{P_{0}}+g
$$

Onde:

$\mathrm{Dt}+1$ = Dividendos por ação esperado em $\mathrm{t}+1$

$\mathrm{g}=$ Taxa de crescimento dos dividendos

$\mathrm{P} 0=$ Preço da ação na data base (D0)

\subsubsection{Custo de capital de terceiros}

Esse coeficiente representa a taxa de retorno exigida pelos credores para a empresa. São os recursos externos que as empresas buscam para financiar suas atividades, como empréstimos e financiamentos.

$$
\mathrm{Kt}=\mathrm{Kd}(1-\operatorname{Tax})
$$


Onde:

$\mathrm{Kd}=$ Custo de capital de terceiros

$\mathrm{Kt}=$ Custo da dívida

Tax $=$ Alíquota efetiva

\subsubsection{Avaliação Relativa}

Enquanto a avaliação por fluxo de caixa descontado estima o valor intrínseco de uma empresa baseado em sua capacidade de gerar fluxos de caixa futuros dado seu histórico passado, a avaliação relativa (ou por múltiplos) baseiase na comparação entre ativos que se enquadram na mesma categoria, podendo levar à conclusão de quais estão supervalorizados. Se o ativo estiver precificado de forma justa, a avaliação do fluxo de caixa descontado e a relativa devem ser coerentes (Damodaran, 2012).

Para esse tipo de avaliação, faz-se necessário o levantamento de quais ativos são comparáveis ao ativo em estudo, chamado de peer group. Para criar preços padronizados é necessário escaloná-los em relação a uma variável comum e em seguida ajustar as diferenças entre os ativos, que ainda que similares, não são iguais (Damodaran, 2012).

\subsubsection{Múltiplos de Lucro}

\subsubsection{Preço por ação / Lucro por ação (P/L)}

$$
\frac{P}{L}=\frac{\text { Preço por ação }}{\text { Lucro por ação }}
$$

Este é um dos múltiplos mais utilizados na análise fundamentalista. Ele representa quantos anos seriam necessários para se obter o valor pago pela ação por intermédio da distribuição de lucros. De outra perspectiva, também indica a quantidade que um investidor espera irá investir na companhia para receber uma 
unidade monetária de volta, ou seja, quanto investidores estão dispostos a pagar por cada unidade monetária lucrada.

Segundo Damodaran (1997), a análise desse múltiplo deve seguir observações de extrema importância, como: o P/L de empresas estabelecidas em economias com alta taxa de juros tende a ser menor que em países com baixa taxa de juros; o P/L de empresas em economias com alta taxa de crescimento tende a ser maior que países com baixo crescimento; o $\mathrm{P} / \mathrm{L}$ de empresas em países mais arriscados costuma ser menor do que em países com menos risco.

\subsubsection{Múltiplos de Receita}

\subsubsection{Preço / Receita (P/S)}

$$
\frac{P}{\text { Rceitas }}=\frac{\text { Preço por ação }}{\text { Receitas totais }}
$$

Este múltiplo compara o preço por ação com a receita (ou vendas). Assim como o índice de lucro, ele avalia o quanto um investidor precisa investir para receber em retorno uma unidade monetária das vendas da companhia. Ou seja, representa o quanto o mercado está disposto a pagar para cada dólar de receita produzida.

\subsubsection{Valor da empresa/ Receitas (EV/S)}

$$
\frac{E V}{\text { Receitas }}=\frac{\text { Enterprise Value }}{\text { Receitas totais }}
$$

O resultado desse múltiplo compara o valor da empresa em um determinado momento com o quanto ela produziu de receita no mesmo período. Esse coeficiente oferece uma estimativa de quanto custaria para comprar as vendas da empresa. 
Essa métrica é uma expansão do coeficiente P/S, pois aqui leva-se em conta as dívidas da empresa, enquanto que no primeiro é utilizado o valor de mercado ${ }^{5}$.

\subsubsection{Múltiplos de patrimônio}

\subsubsection{Preço / Patrimônio Líquido (P/PL)}

$$
\frac{P}{P L}=\frac{\text { Preço }}{\text { Patrimônio Líquido }}
$$

Este índice mostra quanto o mercado está disposto a pagar sobre o PL da empresa, relacionando o preço da ação ao valor patrimonial proporcional a ela. Desse modo, esse coeficiente reflete o valor atrelado pelo mercado à ação em comparação ao seu valor contábil. Um P/PL igual a 1 significa que a ação está sendo negociada pelo equivalente a seu patrimônio líquido. Quando for menor que 1, pode significar que a ação está sendo negociada abaixo do seu preço justo.

\subsubsection{Múltiplos de EBITDA}

\subsubsection{Valor da empresa / EBITDA}

\section{EV \\ EBITDA}

Onde:

$\mathrm{EV}=$ Enterprise Value (Valor da Firma)

Esse índice representa quanto tempo levaria para o lucro operacional da empresa (EBITDA) pagar todo o investimento feito. Por mais que um resultado baixo possa indicar que a empresa está subvalorizada, é importante lembrar que eles

\footnotetext{
${ }^{5}$ Enterprise Value é igual ao valor de mercado somado as dívidas líquidas menos disponibilidades. $\mathrm{O}$ valor de mercado é encontrado ao multiplicar o preço por ação por a quantidade de ações em circulação.
} 
variam de setor. Dentro do mesmo setor, quanto menor o múltiplo mais atraente é a ação. Empresas que apresentam um alto crescimento, como por exemplo as de tecnologia, costumam apresentar múltiplos maiores. Em geral, um coeficiente abaixo de 10 costuma ser interpretado como saudável por analistas e investidores. Segundo Martelanc, Pasin e Cavalcante (2005, p. 207), “A principal vantagem do EBITDA sobre o fluxo de caixa é a simplicidade de sua obtenção a partir dos demonstrativos financeiros. Uma segunda vantagem é o fato de não necessitar de estimativas médias ou projetadas de contas como a de investimentos, que podem oscilar muito em razão dos planos de expansão da empresa. Isso explica a alta popularidade do múltiplo de EBITDA e a baixa utilização do múltiplo do fluxo de caixa.".

\subsection{Informações públicas}

As empresas listadas na bolsa de valores nos Estados Unidos, assim como em qualquer mercado, precisam divulgar suas informações publicamente de forma periódica para a SEC (Security and Exchange Commission) ${ }^{6}$. De modo a recolher informações relevantes para esta pesquisa - preços, margens, aumento de usuários dentre outros -, os relatórios que serão explorados incluem:

- 10 - K: Relatório Anual;

- 10 - Q: Relatório Trimestral;

- Press Releases: Informações lançadas na mídia anterior a publicação do relatório;

- Earnings call: Call com os principais executivos e analistas dos maiores bancos para comentarem os resultados após cada trimestre.

\footnotetext{
${ }^{6}$ Equivalente a CVM no Brasil.
} 


\section{0 mercado de streaming}

\subsection{Evolução e panorama do mercado}

Meios de transmissões tradicionais vêm gradualmente perdendo audiência. (Netflix, 2018). O Rádio foi o meio de entretenimento dominante por quase 50 anos até que a televisão tomar seu lugar na década de 60. Com esse grande avanço, nos últimos 60 anos surgiram empresas ao redor do mundo a fim de satisfazerem os desejos de seus consumidores. Já a era da internet, que começou por volta de uma década, é esperada que seja muito longa, duradoura e transformadora, e que gere ainda muitas disrupções no mercado. Com a ascendência de novas tecnologias e com o aumento do uso de internet, novas plataformas de mídia vêm ganhando popularidade e trazendo um grande desafio às tradicionais formas de comunicação, que lutam por um lugar no mercado. Percebe-se pela figura abaixo o impacto que essas novas tecnologias tiveram na tradicional TV a cabo.

Figura 3: Fatores que influenciam o corte de serviço de satélite/ a cabo.

What factors influenced your decision to cut off your cable/satellite service?

Reasons for cutting the cord in North America 2017

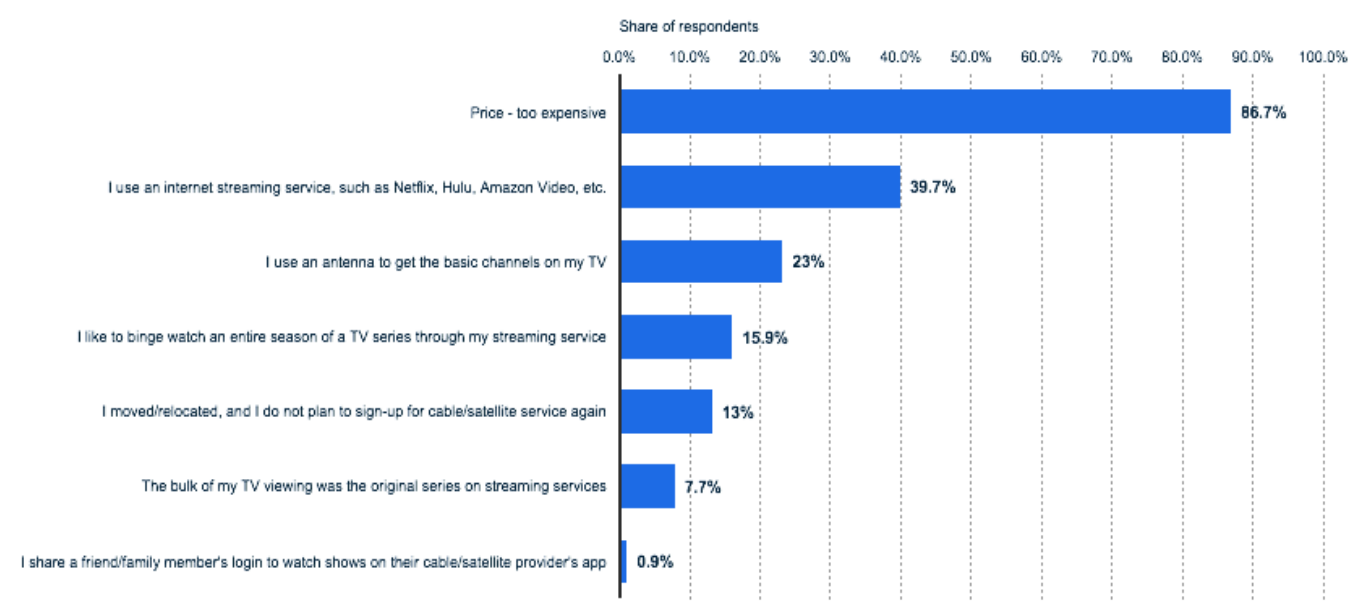

Fonte: Statista, 2019. 
Enquanto gravações físicas perderam espaço no mercado, o serviço de streaming se consolidou como a opção preferida ao redor do mundo. Embora já haja milhares de usuários assinando serviços de streaming, ainda há um potencial enorme de crescimento. Em 2018 nos Estados Unidos, o tempo médio gasto em plataformas de streaming foi de $7 \mathrm{~h}$, enquanto que a média da TV tradicional foi de $2 \mathrm{~h}$. Até 2019 , o total da receita global do mercado de entretenimento deve chegar a mais de U\$2 trilhões, tendo potencial e espaço para crescer muito mais.

Figura 4: Usuários globais do serviço de Streaming de vídeo.

\section{Users in the Video Streaming (SVoD) market}

in millions (worldwide)

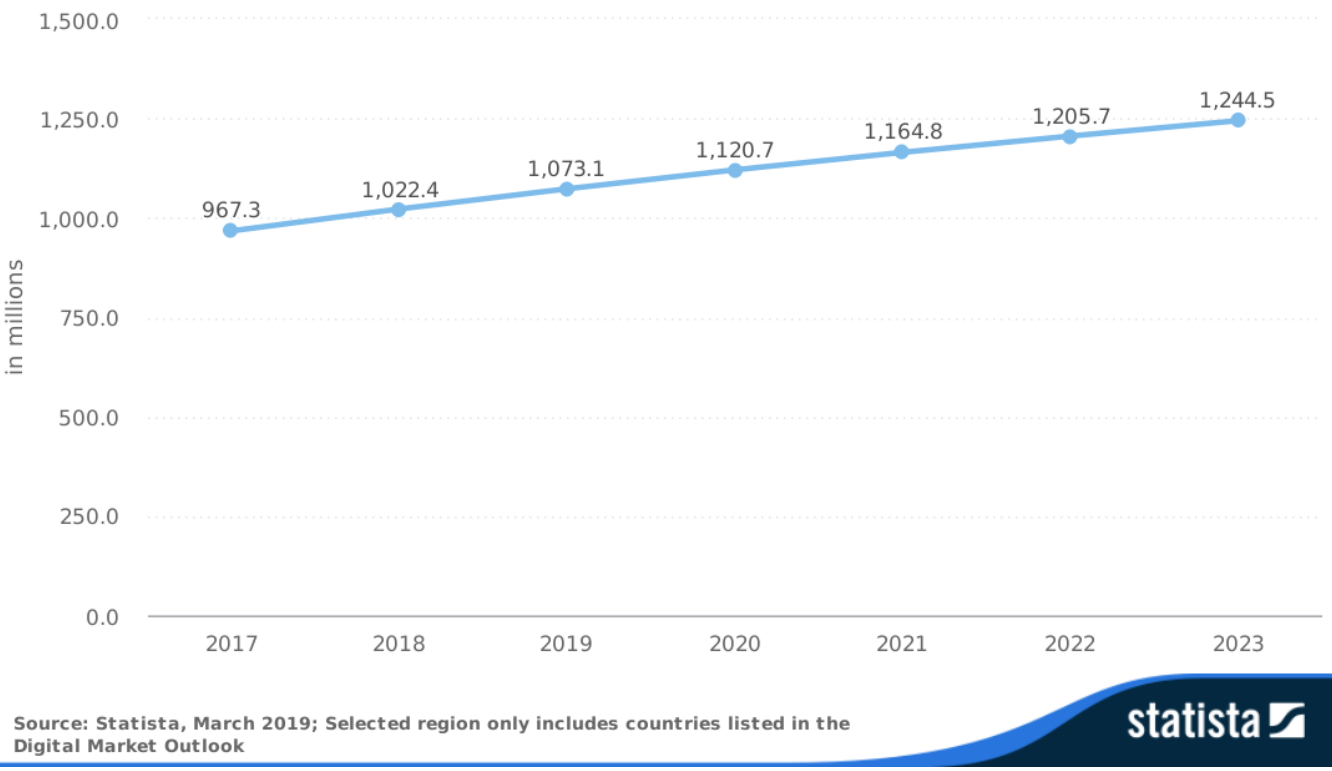

Fonte: Statista, 2019.

\subsection{Principais players}

Com a ascensão e potencial desse mercado de streaming, novos players surgiram de forma bastante competitiva, seja em termos de preço, conteúdo ou posicionamento. O sucesso de plataformas como a Netflix e Spotify fazem com que outros produtos sejam constantemente criados, acirrando ainda mais a competição 
no mercado de streaming. Os principais players e competidores da Netflix são: Amazon, Disney, Hulu, HBO Now e Apple.

O serviço de streaming da Amazon, também conhecido como Prime Video, foi lançado em 2006 e oferece programas de televisão e filmes para aluguel e compra. Os títulos selecionados são oferecidos gratuitamente para os clientes com assinatura na Amazon Prime - um serviço premium oferecido pela Amazon-, que hoje conta com mais de 100 milhões de usuários apenas nos EUA. Tem presença global e em alguns países oferece Amazon Channels, que permite que usuários tenham acesso a outros conteúdos, como por exemplo da HBO. Além de ter acesso a plataforma de filme, a grande vantagem é que a conta vem também com outros serviços oferecidos pela Amazon, como por exemplo frete grátis de até dois dias de entrega, possibilidade de comprar produtos de antemão, dentre outras vantagens. No entanto, para aqueles que não tem uma conta Amazon Prime, alugar um filme custa pelo menos $\$ 2.99$ - somente $\$ 5$ a menos que uma mensalidade da Netflix.

Programado para ser lançado nos Estados Unidos no final de 2019, a Disney+ é o serviço de streaming da Disney que reunirá todos os títulos já produzidos por eles, incluindo conteúdo de Pixar, Marvel, Fox, National Geographic e Lucasfilm. Além de reunir títulos extremamente populares, não se sabe se a Disney irá parar de licenciar seu conteúdo à Netflix. Se isso acontecer, a plataforma irá perder títulos importantes em sua biblioteca. Importante mencionar que a Disney tem uma participação majoritária (60\%) em um outro player significante desse mercado, a Hulu, presente nos Estados Unidos e no Japão. Esta plataforma, no final de 2018, contava com 25 milhões de usuários e é estimado que até o fim de 2019 chegue a 80 milhões. A empresa oferece tanto serviço pago quanto não pago: esta última disponibiliza episódios recentes e limitados, enquanto o pago (Hulu Plus) inclui uma mensalidade de USD 5.99 onde o usuário tem acesso a todo conteúdo disponível na plataforma. O diferencial dessa plataforma é a qualidade de conteúdo produzido (pouca quantidade, mas muita qualidade) e a possibilidade de assinar Hulu with Live TV, que acopla todo conteúdo da plataforma e mais alguns canais da TV aberta, incluindo os da Disney. Em menos de 2 anos após seu lançamento, a Hulu with Live TV chegou a 1 milhão de usuários. 
Dona de títulos importantes, como Game of Thrones e True Detective, a HBO Now é uma plataforma baseada em assinatura, que conta com 150 milhões de usuários ao redor do mundo. De acordo com uma pesquisa realizada no final de 2017, a HBO foi a plataforma que os americanos estavam dispostos a pagar o maior valor para ter tal serviço. Assim como a Hulu, a HBO foca em conteúdos de maior qualidade em vez de focar na quantidade.

Por mais que não tenha lançado seu serviço de streaming ainda, a Apple já pode ser considerada uma player por já disponibilizar conteúdo para compra ou aluguel em sua plataforma. Além disso, a empresa já anunciou sua plataforma de streaming, a Apple TV+, que irá produzir conteúdo próprio para ser distribuído via Apple TV, iPhone e iPads, além de contar com conteúdo de terceiros como inclusive da HBO. O preço pelo serviço ainda não foi divulgado, mas é uma plataforma mundial promissora, que está gerando alta expectativa no mercado.

Para manter as coisas em perspectivas, a tabela abaixo apresenta o Market Share e preço mensal médio de cada uma das plataformas mencionadas ${ }^{7}$ :

Tabela 1: Plataformas de streaming: preço e market share

\begin{tabular}{|c|c|c|}
\cline { 2 - 3 } \multicolumn{1}{c|}{} & Preço médio mensal em USD & Market share nos EUA \\
\hline Netflix & 10.99 & $51 \%$ \\
\hline Amazon & 8.99 & $22.1 \%$ \\
\hline Hulu & 9.99 & $12.9 \%$ \\
\hline HBO Now & 14.99 & $5.4 \%$ \\
\hline Hulu with Live TV & 40.00 & $2 \%$ \\
\hline
\end{tabular}

Fonte: Statista, 2019.

\footnotetext{
${ }^{7}$ Serviço de streaming da Disney e Apple ainda não foram lançados, por isso não há dados para eles.
} 


\section{Netflix}

\subsection{História}

Netflix é a pioneira e líder mundial de streaming. A empresa foi fundada por Reed Hastings e Marc Randolph em 1997 oferecendo serviço de entrega de DVD pelo correio, lançando o serviço de streaming apenas 20 anos depois como um serviço complementar ao business de DVD. A lógica inicial do negócio seria muito similar àquele das locadoras tradicionais: o usuário escolheria o filme pela internet, recebia o DVD em sua casa pelos correios, e faria a devolução da mesma forma. A empresa começou sua operação com um time de 30 pessoas e uma coleção de 925 DVDs. Em 1999, dois anos após a criação da marca, os fundadores acabaram fazendo uma oferta para a Blockbuster, a maior rede de locadora do mundo até então, por USD 50 milhões. Desacreditando na premissa e no potencial da Netflix, a Blockbuster acabou declinando a oferta, e em 2010 anunciou sua falência.

Foi a partir de 2007 que a empresa começou a se destacar e se posicionar bem diante de mudanças tecnológicas e das preferências do consumidor. Enquanto a tecnologia evoluía para permitir o streaming, a Netflix se adaptou e lançou o serviço de video on demand, enquanto que os estabelecimentos tradicionais, não.

Dentro de um ano após lançado o online streaming, o mesmo cresceu tanto que a empresa redefiniu seu canal para o online (Cook, 2014). Em 2010 iniciou seu processo de expansão iniciando pelo Canadá, e hoje já se faz presente no mundo todo, com exceção de certos lugares, como por exemplo a Coreia do Norte devido a problemas regulamentários (Statista, 2018). A plataforma conta com quase 160 milhões de usuários e com um valor de mercado de USD 157 Bi, valendo mais de 140 vezes seu valor inicial (Yahoo Finance, 20 de abril 2019). No primeiro semestre de 2018 chegou inclusive a valer mais que a Disney. 
Figura 5: Valorização da Netflix (jan/2009 até fev/2019).

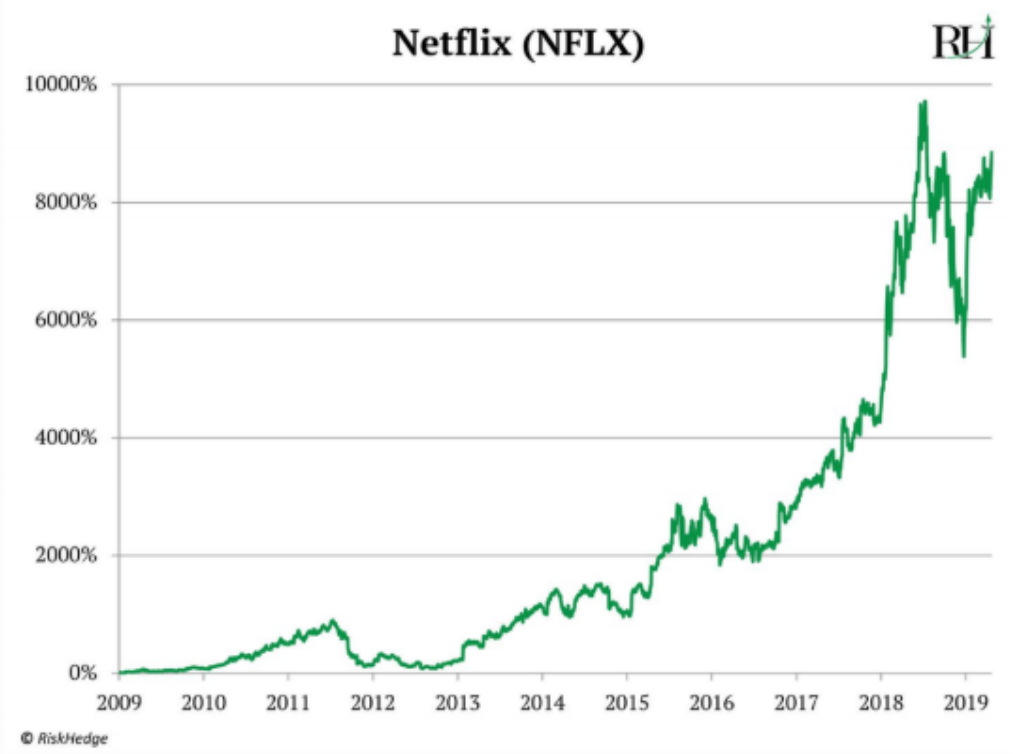

Fonte: Forbes, 2019.

A empresa oferece três planos diferentes: o plano básico, que permite acesso a apenas uma tela por vez, o plano standard (mais popular) que oferece duas telas por vez, e o plano "premium" que oferece acesso a quatro telas por vez com ultra definição. O preço varia dependendo do lugar, conforme tabela abaixo (preços em USD):

Figura 6: Preço cobrado pelo serviço em diferentes regiões.

\begin{tabular}{lcccc} 
Country & Basic & Standard & Premium & $\begin{array}{c}\% \text { of average } \\
\text { disp. Income }\end{array}$ \\
\hline United States & $\$ 7.99$ & $\$ 10.99$ & $\$ 13.99$ & $0.3 \%$ \\
Canada & $\$ 6.84$ & $\$ 8.37$ & $\$ 10.65$ & $0.3 \%$ \\
Mexico & $\$ 5.68$ & $\$ 7.76$ & $\$ 10.37$ & $1.1 \%$ \\
United Kingdom & $\$ 7.93$ & $\$ 10.58$ & $\$ 13.22$ & $0.4 \%$ \\
France & $\$ 9.35$ & $\$ 12.86$ & $\$ 16.37$ & $0.5 \%$ \\
Germany & $\$ 9.35$ & $\$ 12.86$ & $\$ 16.37$ & $0.5 \%$ \\
Spain & $\$ 9.35$ & $\$ 12.86$ & $\$ 16.37$ & $0.8 \%$ \\
Italy & $\$ 9.35$ & $\$ 12.86$ & $\$ 16.37$ & $0.6 \%$ \\
Switzerland & $\$ 11.96$ & $\$ 15.98$ & $\$ 19.99$ & $0.3 \%$ \\
Russia & $\$ 9.35$ & $\$ 11.69$ & $\$ 14.03$ & $1.7 \%$ \\
Japan & $\$ 5.84$ & $\$ 8.53$ & $\$ 13.03$ & $0.3 \%$ \\
India & $\$ 7.26$ & $\$ 9.44$ & $\$ 11.62$ & $2.1 \%$ \\
Australia & $\$ 7.43$ & $\$ 10.40$ & $\$ 13.37$ & $0.3 \%$ \\
Brazil & $\$ 5.14$ & $\$ 7.20$ & $\$ 9.79$ & $1.0 \%$ \\
Argentina & $\$ 4.62$ & $\$ 6.05$ & $\$ 8.20$ & $0.6 \%$ \\
Chile & $\$ 7.05$ & $\$ 9.20$ & $\$ 11.36$ & $1.0 \%$
\end{tabular}

Fonte: Statista, 2018. 


\subsection{Principais ameaças e oportunidades}

Produzir seu próprio conteúdo em vez de comprar direitos de filme foi uma das maiores oportunidades identificadas pela Netflix, que hoje é um dos pontochaves de seu negócio. Além de contar com conteúdo produzido por outros estúdios, a própria Netflix vem se tornando um estúdio. Em 2016, a empresa contava com 4\% de conteúdo original na sua livraria, enquanto que em 2018 esse número já havia crescido para 11\% (levando em conta também que em 2018 tinha uma gama muito maior de títulos totais disponíveis) (Netflix, 10-K). Nesse mercado tão competitivo, aquele que produzir o melhor conteúdo terá uma grande vantagem competitiva forte. A pergunta que permanece é se isso é definido por quantidade ou qualidade...

Sem dúvida alguma, o mercado de streaming tem um potencial gigante. Ainda com pouca penetração, consumidores em geral tendem a preferir esse modelo e o crescimento deste mercado não há previsão de diminuir tão cedo. Por ser líder e pioneira, e ter a maior fatia de mercado dentre as outras plataformas, a Netflix tem uma vantagem competitiva gigante.

O DVD como correio, a ascensão do streaming, e a produção de conteúdo próprio da Netflix foram ameaças que a empresa sofria e que conseguiu torná-las em oportunidades. Sem dúvida alguma, a empresa conseguiu mudar tanto o jeito como filmes e entretenimento são criados, quanto a forma que consumidores optam por assistí-los. Dentre tantas oportunidades e vitórias da empresa, há certos desafios pouco mencionados, mas que podem ser prejudiciais no longo prazo.

A Netflix opera num mercado de competição intensa, sem sinal de melhora. Milhares de plataformas estão competindo por um espaço da carteira e do tempo do consumidor. No momento a Netlix é a líder nesse mercado, com a maior produção de conteúdo, mas caso uma gigante como a Amazon decida investir significantemente em streaming, a Netflix teria que lidar com uma competição ainda mais agressiva.

Devido a um cenário mais saturado com outros players que oferecem o mesmo serviço com preços mais atrativos, a Netflix vem encarando uma certa dificuldade de penetração em mercados emergentes promissores, como por 
exemplo a Índia. Em mercados relevantes, como os Estados Unidos, o nível de penetração da empresa já é considerado bastante alto (no primeiro trimestre de 2019, a empresa contava com 62 milhões de usuários norte-amercianos), sendo difícil aumentar de forma significativa sua base de clientes neste mercado. A dificuldade de se estabelecer em mercados emergentes, portanto, complica sua estratégia de expansão, um ponto fundamental para uma empresa se manter viva num setor tão dinâmico quanto o de mídia. No entanto, o maior upside da empresa é a sua expansão internacional, e onde a empresa mais tem crescido. Se a Netflix conseguir dominar mercados internacionais, terá um enorme potencial.

Como mencionado anteriormente, a atratividade do mercado fez com que até mesmo as gigantes bem estabelecidas no mercado, como a Disney, entrasse para o meio de streaming. Com empresas oferecendo o mesmo serviço que a Netflix com preços mais competitivos, torna-se ainda mais difícil para a empresa em estudo ocupar uma parcela na carteira de assinaturas do consumidor. A Disney já anunciou seu preço: USD 6.99 mensal, apenas um pouco mais que metade do preço da Netflix - sem contar que há a possibilidade de todo seu conteúdo original ser removido da plataforma. Outra vantagem enfrentada pela Disney é que enquanto a Netflix gasta quantidades alarmantes para produção de novos conteúdos, a primeira já tem sua gama clássica e tradicional de conteúdo, que aparentou ter uma vida muito mais longa que o que é produzido pela Netflix.

Fora isso, a empresa investe muito em conteúdo. Alguns dirão que até mais do que poderia, uma vez que isso resulta em fluxo de caixa cada vez mais negativo. Somente em 2018, a empresa gastou USD 12.04 bilhões em conteúdo vs. USD 8.9 bilhões em 2017, um aumento de 35\%. Para o ano de 2019, é esperado um gasto de USD 15 bilhões. Caso outros produtores resolvam tirar seu conteúdo da plataforma, o mesmo pode se tornar ora proibido à Netflix ou então muito além do limite de preço que a empresa está disposta a pagar. Apenas trazendo um exemplo prático, no final de 2018 a Netflix pagou USD100 milhões para manter o seriado Friends em sua plataforma apenas pelo ano de 2019.

Além disso, eles vêm dependendo de níveis crescentes de dívida líquida como forma de financiar seu conteúdo original. No final de 2018, eles deviam 59\% a mais para seus credores do que no mesmo período em 2017. Isso pode vir a ser 
insustentável no caso de uma reviravolta no mercado - mais precisamente falando, no caso de uma curva de juros invertida e/ou uma eventual crise, um assunto extremamente recorrente sobre o mercado norte-americano. O rápido crescimento empresarial junto a financiamento com taxas baixas dá certo até que um deles pare de funcionar, e isso forçaria a empresa a cortar custos com conteúdo.

Tabela 2: Evolução da dívida de longo-prazo.

\begin{tabular}{|l|c|c|c|}
\cline { 2 - 4 } \multicolumn{1}{c|}{} & $\mathbf{2 0 1 8}$ & $\mathbf{2 0 1 7}$ & $\mathbf{2 0 1 6}$ \\
\cline { 2 - 4 } \multicolumn{1}{c|}{} & \multicolumn{3}{c|}{ (em milhares) } \\
\hline $\begin{array}{l}\text { Caixa e equivalentes e } \\
\text { investimentos de curto prazo }\end{array}$ & $\$ 3,812,041$ & $\$ 2,822,795$ & $\$ 1,733,782$ \\
\hline Dívida de longo prazo & $\$ 10,360,058$ & $\$ 6,499,432$ & $\$ 3,364,311$ \\
\hline
\end{tabular}

Fonte: Netflix, 2019.

\subsection{Estrutura administrativa}

\subsubsection{Estrutura acionária}

Tabela 3: Estrutura acionária por Tipo de Investidor e Tipo de Acionista.

\begin{tabular}{|l|c|}
\cline { 2 - 2 } \multicolumn{1}{c|}{} & $\%$ \\
\hline Consultoras de Investimento e Executivos & 90,62 \\
\hline Bancos & 2,46 \\
\hline Fundos de pensão & 2,15 \\
\hline Pessoas Físicas & 1,65 \\
\hline Governo & 1,54 \\
\hline Fundo soberano & 0,98 \\
\hline Seguradoras & 0,99 \\
\hline
\end{tabular}

Fonte: Bloomberg, 2019. 


\subsubsection{Conselho de administração}

Tabela 4: Formação do Conselho de administração.

\begin{tabular}{|l|c|c|}
\hline Membro do Conselho & \multicolumn{1}{|c|}{ Cargo } & Início \\
\hline Reed Hastings* & CEO e Presidente do Conselho & 1997 \\
\hline Jay Crandall Hoag & Diretor Principal (independente) & 2013 \\
\hline Timothy Haley & Membro do conselho (independente) & 2002 \\
\hline Richard Barton & Membro do conselho (independente) & 2002 \\
\hline Ann Mather & Membro do conselho (independente) & 2010 \\
\hline Leslie Kilgore & Membro do conselho (independente) & 2012 \\
\hline Bradford Smith & Membro do conselho (independente) & 2015 \\
\hline Anne Sweeney & Membro do conselho (independente) & 2015 \\
\hline Rodolphe Belmer & Membro do conselho (independente) & 2018 \\
\hline Susan Elizabeth Rice & Membro do conselho (independente) & 2018 \\
\hline Mathias Doespfner & Membro do conselho (independente) & 2018 \\
\hline
\end{tabular}

Fonte: Bloomberg, 2019.

*Co-fundador da companhia

\subsubsection{Diretoria Executiva}

Tabela 5: Diretoria Executiva.

\begin{tabular}{|l|c|c|}
\hline \multicolumn{1}{|c|}{ Nome } & Cargo & Início \\
\hline Reed Hastings & Co-fundador, Presidente e CEO & 1997 \\
\hline Spencer Neumann & CFO & 2019 \\
\hline Kelly Bennett & Diretora de Marketing & 2012 \\
\hline David Hyman & Conselheiro Geral e Secretário & 2002 \\
\hline Jessica Neal & Diretora de Recursos Humanos & 2017 \\
\hline Greg Peters & Diretor de Produto & 2017 \\
\hline Ted Sarandos & Diretor de Conteúdo & 2000 \\
\hline Rachel Whetstone & Diretora de Comunicação & 2018 \\
\hline
\end{tabular}

Fonte: Bloomberg, 2019. 


\subsubsection{Comitês}

Pelo conselho de administração foram estabelecidos três conselhos:

1. Comitê de Remuneração

2. Comitê de Auditoria

3. Comitê de Governança e Indicação

Os membros dos comitês são formados pelos conselheiros, que podem ser indicados a qualquer momento pelo conselho de administração. Os conselheiros têm que atender pelo menos $75 \%$ das reuniões ocorridas no ano. Conforme mostrado nas seções subsequentes, todos os membros do conselho, tirando o CEO e co-fundandor da empresa, são independentes. Isso é de extrema importância pois assegura aos acionistas um monitoramento profissional, técnico e desvinculado de interesses e influências de terceiros.

\subsubsection{Comitê de Remuneração}

Tem como objetivo elaborar e propor a todo o Conselho a política de remuneração dos executivos da Netflix. Os membros deste comitê têm que ser independentes.

Tabela 6: Membros do Comitê de Remuneração.

\begin{tabular}{|l|c|}
\hline \multicolumn{1}{|c|}{ Membros } & Cargo \\
\hline Timothy Haley & Presidente do Comitê de Remuneração \\
\hline Rodolphe Belmer & Membro do Comitê de Remuneração \\
\hline Mathias Doespfner & Membro do Comitê de Remuneração \\
\hline Anne Sweeney & Membro do Comitê de Remuneração \\
\hline
\end{tabular}

Fonte: Bloomberg, 2019. 


\subsubsection{Comitê de Auditoria}

Este comitê é responsável por assegurar os processos de auditoria interna e externa, avaliar os controles financeiros e resultados fiscais, assim como os mecanismos de controles relacionados a gestão de riscos. Fica sob os cuidados deste Comitê checar com os colaboradores todos os resultados antes de serem divulgados aos acionistas e ao público em geral.

Tabela 7: Membros do comitê de Auditoria.

\begin{tabular}{|l|c|}
\hline \multicolumn{1}{|c|}{ Membros } & Cargo \\
\hline Ann Mather & Presidente do Comitê de Auditoria \\
\hline Richard Barton & Membro do Comitê de Auditoria \\
\hline Leslie Kilgore & Membro do Comitê de Auditoria \\
\hline
\end{tabular}

Fonte: Bloomberg, 2019.

\subsubsection{Comitê de Governança e Indicação}

Avaliam e indicam candidatos para o Conselho e são responsáveis pelo monitoramento das práticas de governança corporativa.

Tabela 8: Membros do comitê de Governança e Indicação.

\begin{tabular}{|l|c|}
\hline \multicolumn{1}{|c|}{ Membros } & Cargo \\
\hline Jay Crandall Hoag & Presidente do Comitê de Governança e Indicação \\
\hline Bradford Smith & Membro do Comitê de Governança e Indicação \\
\hline Susan Elizabeth Rice & Membro do Comitê de Governança e Indicação \\
\hline
\end{tabular}

Fonte: Bloomberg, 2019. 


\subsection{Valuation}

\subsubsection{Valuation baseado no valor do usuário: subscription-based approach}

Dado que o fluxo de caixa terminal da Netflix é negativo ${ }^{8}$, o valuation será realizada baseado em seus usuários. Os dados foram retirados dos relatórios anuais da empresa, o 10-K e da plataforma Bloomberg 9 . Para chegar no valor justo, o estudo foi dividido da seguinte maneira:

- Cálculo de custo de capital

- Definição do valor de usuários já existentes

- Definição do valor de novos usuários

- Abertura e análise dos custos e despesas,

○ Definir quais custos podem ser relacionados a usuários novos e existentes

○ Definir custos corporativos, ou seja, aqueles que não são atrelados diretamente a nenhum usuário, e que a empresa incorrerá independente da sua base de clientes.

Para realizar a valuation tendo uma abordagem baseada em seus usuários, é necessário realizar uma abertura dos custos, definindo o que é relacionado a novos usuários, a usuários existentes, e também quais custos podem ser relacionados a empresa. Como a empresa não divulga isso de forma relacionada, as premissas da Tabela XX foram criadas. Como suposição, os custos de marketing são $100 \%$ relacionados a captação de novos usuários, os custos gerais e administrativos são 100\% relacionados a usuários já existentes, e os custos de conteúdo foi dividido da seguinte forma: $30 \%$ relacionados aos usuários, e $70 \%$ relacionado como custo corporativo, ou seja, a empresa terá essa segunda parcela de gasto com conteúdo independentemente do seu número de usuários.

\footnotetext{
${ }^{8}$ Diante posicionamento deste estudo

${ }^{9}$ Empresa de tecnologia e dados que distribui informação econômica e financeira.
} 
Tabela 9: Premissas adotadas para o valuation.

\begin{tabular}{|c|c|}
\hline Tempo de vida de um usuário & 10 anos \\
\hline Probabilidade de renovação do serviço & $90 \%$ \\
\hline $\begin{array}{l}\text { Taxa de crescimento do preço cobrado pela } \\
\text { empresa }\end{array}$ & $10 \%$ \\
\hline $\begin{array}{l}\text { Taxa de crescimento no custo de serviço } \\
\text { por usuário }\end{array}$ & $2 \%$ \\
\hline \multirow{3}{*}{ Taxa de crescimento de usuários } & - Anos 1 a $5: 15 \%$ \\
\hline & - Anos 6 a 10: $10 \%$ \\
\hline & - Após 10 anos: 3\% \\
\hline $\begin{array}{l}\text { Crescimento de custos de tecnologia pelos } \\
\text { próximos } 10 \text { anos }\end{array}$ & $5 \%$ \\
\hline $\begin{array}{l}\text { Crescimento de custos de conteúdo pelos } \\
\text { próximos } 10 \text { anos }\end{array}$ & $3 \%$ \\
\hline Custos de marketing & Destinado $100 \%$ para novos usuários \\
\hline Custos Gerais e Administrativos (G\&A) & Destinado $100 \%$ para usuários existentes \\
\hline Custos corporativos & $\begin{array}{c}\text { Não são diretamente relacionados com o } \\
\text { usuário. }\end{array}$ \\
\hline Custos de conteúdo & $\begin{array}{l}30 \% \text { atribuível para usuários. Os outros } \\
70 \% \text { identificados como custo corporativo. } \\
\text { Considera-se também que os custos de } \\
\text { conteúdo atuais são } 100 \% \text { destinados para } \\
\text { usuários existentes. }\end{array}$ \\
\hline Custo de capital & $\begin{array}{l}\text { O mesmo tanto para usuários já existentes } \\
\text { quanto para novos usuários. }\end{array}$ \\
\hline
\end{tabular}

Fonte: Próprio autor (2019).

\subsubsection{Custo Médio de Capital Ponderado (WACC)}

O custo de capital ponderado é a taxa mínima exigida por um investidor ao optar por um investimento em vez de outro, e, portanto, representa a taxa de desconto utilizada em uma análise de retorno. As variáveis para o cálculo dessa taxa são:

Tabela 10: Variáveis para o cálculo do custo de capital.

\begin{tabular}{|l|c|}
\hline Taxa livre de risco & $2,68 \%$ \\
\hline Prêmio de risco de ações (EUA) & $11,79 \%$ \\
\hline Beta & 1,47 \\
\hline Retorno esperado do mercado & $10,71 \%$ \\
\hline Taxa efetiva & $1,24 \%$ \\
\hline
\end{tabular}

Fonte: Bloomberg, 2019. 
Com tais variáveis definidas, foi possível encontrar o custo do capital próprio $(\mathrm{Ke})$ e o custo do capital de terceiros $(\mathrm{Kd})$. Os cálculos referentes a essa forma de avaliação foram mostrados anteriormente.

Tabela 11: WACC da Netflix

\begin{tabular}{|l|c|c|c|}
\cline { 2 - 4 } \multicolumn{1}{c|}{} & Ke & Kd & Total \\
\hline Valor (USD) & 116.860 & $10.360,1$ & 127220,19 \\
\hline Peso (\%) & 0,91857 & 0,08143 & 1,00 \\
\hline WACC & 0,14484 & 0,0429 & $\mathbf{1 3 , 6 5 \%}$ \\
\hline
\end{tabular}

Fonte: Próprio autor (2019).

\subsubsection{Valor de usuários existentes}

Os custos associados a usuários existentes são relativamente pequenos: custos administrativos e apenas 30\% do custo de conteúdo. Como premissa, a probabilidade de renovação por usuário é de 90\% (em 2017 a taxa foi de 91\%).

Usando o custo de capital para trazer as projeções ${ }^{10}$ para valor presente, chegou-se no valor de USD 426,72 por usuário. Multiplicando esse resultado pela quantidade de assinantes da plataforma, foi possível calcular o valor dos assinantes existentes: USD 63.313,18 milhões.

Tabela 12: Valor de usuários existentes

\begin{tabular}{|l|c|}
\hline Valor por usuário (USD) & $\$ 426,72$ \\
\hline Quantidade de usuários (milhões) & 148,37 \\
\hline Valor de Usuários Existentes (milhões) & $\mathbf{\$ 6 3 . 3 1 3 , 1 8}$ \\
\hline
\end{tabular}

Fonte: Próprio autor (2019).

${ }^{10}$ Para cálculos e informações completas vide Apêndice 1 


\subsubsection{Valor de usuários novos}

O Primeiro passo foi calcular o lucro por usuário. Para isso, estimou-se o custo de adquirir um novo usuário adicionando o custo total de marketing com os $70 \%$ de custo de conteúdo no ano mais recente. Em seguida, esse valor foi dividido pelo aumento de usuários no mesmo período (30,77 milhões). Isso resultou num custo de \$111,39 para adquirir um novo usuário. Esse valor foi subtraído do valor de um usuário existente calculado anteriormente, resultando num lucro por usuário de $\$ 315,34$.

Tabela 13: Lucro de usuários novos no ano corrente.

\begin{tabular}{|l|l|}
\hline Custo de adquirir novos usuários (USD) & $\$ 111,39$ \\
\hline Lucro por usuário (USD) & $\$ 315,34$ \\
\hline
\end{tabular}

Fonte: Próprio autor (2019).

Para calcular o valor adicionado por novos usuários, foi preciso encontrar a quantidade de usuários novos, o valor por cada usuário e o valor adicionado por novos usuários - levando em conta o lucro.

Para encontrar o número de novos usuários, multiplicou o número de usuários no ano base pela taxa esperada de crescimento de usuário e pela probabilidade de renovação. Esse resultado permite projetar o número total de usuários, multiplicando o número de usuários do ano anterior pela probabilidade de renovação, e adicionando o número de novos usuários calculado. Para encontrar o valor adicionado por novos usuários basta multiplicar o lucro por usuário pela taxa de aumento esperado de preço, levando em consideração a quantidade de usuários. Com isso foi possível calcular o valor terminal de novos usuários. Trazendo as projeções para o valor presente e descontando ao custo de capital da empresa, o valor adicionado por novos usuários resultou em USD 187.649,73 milhões ${ }^{11}$.

\footnotetext{
${ }^{11}$ Para cálculos e informações completas vide Apêndice 2
} 
Tabela 14: Valor adicionado por novos usuários

\section{Valor adicionado novos usuários (USD milhões)}

$\$ 187.649,73$

Fonte: Próprio autor (2019).

\subsubsection{Custos corporativos}

Os custos corporativos incluem os de Tecnologia \& Desenvolvimento e $70 \%$ dos custos de conteúdo. Assumiu-se que os custos de tecnologia irão aumentar $5 \%$ pelos próximos 10 anos, enquanto que os de conteúdo vão crescer 3,50\%. Importante notar que mesmo dado uma baixa taxa de crescimento de gasto com conteúdo, a Netflix se encontra entre uma das empresas que mais gasta com produção, investido mais de $\$ 100$ bilhões ao longo desses 10 anos.

Adicionando os custos e descontando impostos (25\%), foi possível calcular o valor terminal dos custos corporativos e trazer as entradas para valor presente, descontando os valores ao custo de capital da empresa. Os custos corporativos resultaram num valor de USD 134.345,26 milhões ${ }^{12}$.

Tabela 15: Custos Corporativos

$$
\text { Total Custos Corporativos (USD milhões) }
$$

$\$ 134.354,26$

Fonte: Próprio autor (2019).

\subsubsection{Valor Justo da Ação}

Por fim, para fazer o valuation da Netflix, realizou-se a soma e subtração dos valores calculados, como indicado na Tabela 16:

\footnotetext{
${ }^{12}$ Para cálculos e informações completas vide Apêndice 3
} 
Tabela 16: Calculando o preço justo por ação da Netflix

\begin{tabular}{|l|c|}
\hline \multicolumn{2}{|c|}{ Valuation } \\
\hline Valor de Usuários Existentes & $\$ 63.313,18$ \\
\hline Valor de Novos Usuários & $\$ 187.649,73$ \\
\hline - PV de gastos & $\$ 134.354,26$ \\
\hline Ativos operacionais & $\$ 116.608,66$ \\
\hline + Caixa & $\$ 3.794,00$ \\
\hline - Dívida & $\$ 10.360,00$ \\
\hline Equity & $\mathbf{\$ 1 1 0 . 0 4 2 , 6 6}$ \\
\hline - Valor de Equity de Opções & $\$ 2.560,00$ \\
\hline Valor de Equity de Ações Ordinárias & $\mathbf{\$ 1 0 7 . 4 8 2 , 6 6}$ \\
\hline Número de ações & 437 \\
\hline Preço justo por ação & $\mathbf{\$ 2 4 6 , 1 8}$ \\
\hline
\end{tabular}

Valor da ação em 31/12/2018

$\$ 267,66$

Fonte: Próprio autor (2019).

O preço justo da ação calculado neste trabalho de $\$ 246,18$ está abaixo do preço de mercado da empresa, de $\$ 267.66$. Pode-se dizer, portanto, que o preço da ação está acima do que ela vale, e a empresa está supervalorizada.

\subsubsection{Avaliação Relativa}

A avaliação relativa da empresa foi dividida em duas partes. Primeiro a comparação será realizada entre índices do mesmo ano (2018) mas de empresas diferentes. Para uma análise relativa consistente, as firmas escolhidas não podem ser aleatórias. Para isso, foram escolhidas três empresas do peer group ${ }^{13}$ da Netflix. Assim será possível uma comparação coesa e coerente. Em seguida será analisada a evolução desses mesmos múltiplos mas somente da Netflix ao longo de 4 anos (2015 a 2018).

\footnotetext{
${ }^{13}$ Peer group pode ser definido como empresas competidoras da mesma indústria e que são parecidas em termos de tamanho. São, portanto, empresas comparáveis.
} 


\subsubsection{1. Índices do peer group}

Como mencionado anteriormente, para realizar a avaliação relativa deve-se considerar empresas do mesmo setor para que a comparação seja coesa e consistente. Para isso, foram selecionadas três empresas do peer group da Netflix: Disney, Viacom e CBS Corp. A Tabela 17 representa os múltiplos das empresas mencionadas.

Tabela 17: Análise comparativa da Netflix e de peers do ano de 2018

\begin{tabular}{|l|c|c|c|c|}
\hline \multicolumn{5}{|c|}{ Índices comparativos 2018 } \\
\hline & Netflix & Disney & Viacom & CBS Corp \\
\hline Preço/Lucro (P/E) & 99,87 & 16,81 & 8,20 & 8,42 \\
\hline Preço/ Vendas (P/V) & 7,38 & 2,95 & 1,05 & 1,14 \\
\hline $\begin{array}{l}\text { Valor da empresa / Vendas } \\
\text { (EV/S) }\end{array}$ & 7,81 & 3,32 & 1,73 & 1,80 \\
\hline Preço/Patrimônio Líquido (P/B) & 22,31 & 3,60 & 1,84 & 5,82 \\
\hline $\begin{array}{l}\text { Valor da empresa/ EBITDA } \\
\text { (EV/EBITDA) }\end{array}$ & 73,10 & 11,08 & 8,06 & 8,74 \\
\hline Preço por Ação (USD) & 267,66 & 116,94 & 33,76 & 43,85 \\
\hline $\begin{array}{l}\text { Valor da empresa (EV) } \\
\text { (milhões de USD) }\end{array}$ & $123.425,6$ & $197.328,0$ & $22.437,7$ & $26.137,6$ \\
\hline
\end{tabular}

Fonte: Bloomberg (2019).

Quanto maior o múltiplo de lucro, maior a probabilidade da empresa estar sobrevalorizada. $\mathrm{O}$ resultado acima demonstra que investidores estão dispostos a pagar USD 99,87 por cada USD 1,00 de lucro corrente d Netflix. Ou seja, investidores esperam que no futuro a empresa gere quase 100x do lucro atual. Esse valor é bem mais baixo ao olhar para outras empresas, chegando a ser 8,20x para a Viacom.

Os múltiplos de receita da Netflix também estão bem acima quando comparado a de seus peers. Nesse caso, investidores estão dispostos a pagar 7,4x (ou 7,8x levando em conta as dívidas da empresa) o que a empresa tem de receita, ou de vendas. O segundo maior múltiplo, da Disney, é menos que a metade do que apresentado pela Netflix.

O múltiplo de patrimônio líquido mostra qual a proporção do valor de mercado da empresa em relação àquilo mostrado no Balanço Patrimonial. O 
resultado da Netflix significa que no mercado ela está sendo avaliada 22,3x a mais do valor apresentado no seu Balanço. O menor múltiplo apresentado é o da Viacom, e é menos que 10 vezes o apresentado pela Netflix.

O último múltiplo a ser analisado é o do EBITDA. Ainda que o múltiplo da Disney esteja um pouco alto para o que é considerado saudável, está dentro da média do apresentado pelo $\mathrm{S} \& \mathrm{P} 500^{14}$, que variou de 11 a 14 nos últimos anos. Enquanto os índices da Fox e Viacom parecem estar um pouco abaixo, o da Netflix destoa muito do que é apresentado pelas empresas em análise.

Importante perceber aqui que por mais que o valor da empresa (EV) apresentado pela Disney é maior que o da Netflix, o coeficiente da Disney é mais baixo que os apresentados pela empresa em análise. Ou seja, mesmo tendo um numerador menor, a Netflix apresenta múltiplos maiores que a Disney.

As últimas duas linhas representam o preço por ação da empresa e o Enterprise Value, apenas para manter as coisas em perspectivas ao fazer esse tipo de análise.

\subsubsection{Múltiplos da Netflix}

A tabela a seguir reúne os múltiplos da Netflix numa janela retroativa de 4 anos: de 2018 a 2015. Para facilitar a compreensão e comparação desses múltiplos ao longo do ano, foram criados gráficos em cada tópico deste capítulo.

\footnotetext{
${ }^{14}$ S\&P500 é um índice da bolsa americana, que reúne 500 empresas mais representativas e negociadas na NYSE e na Nasdaq.
} 
Tabela 18: Múltiplos da Netflix de 2015 a 2018.

\begin{tabular}{|l|c|c|c|c|}
\hline \multicolumn{7}{|c|}{ Índices Netflix } \\
\hline & $\mathbf{2 0 1 8}$ & $\mathbf{2 0 1 7}$ & $\mathbf{2 0 1 6}$ & $\mathbf{2 0 1 5}$ \\
\hline Preço/Lucro (P/E) & 99,87 & 143,80 & 287,91 & 408,50 \\
\hline Preço/Vendas (P/S) & 7,38 & 7,09 & 6,01 & 7,19 \\
\hline $\begin{array}{l}\text { Valor da empresa/Vendas } \\
\text { (EV/S) }\end{array}$ & 7,81 & 7,43 & 6,21 & 7,23 \\
\hline $\begin{array}{l}\text { Preço/ Patrimônio Líquido } \\
\text { (P/PL) }\end{array}$ & 22,31 & 23,23 & 19,87 & 22,01 \\
\hline $\begin{array}{l}\text { Valor da empresa/ EBITDA } \\
\text { (EV/EBITDA) }\end{array}$ & 73,10 & 95,40 & 125,47 & 133,14 \\
\hline Preço por Ação (USD) & 267,66 & 191,96 & 123,80 & 114,38 \\
\hline $\begin{array}{l}\text { Valor da empresa (EV) } \\
\text { (milhões de USD) }\end{array}$ & $123.425,6$ & $86.870,7$ & $54.871,2$ & $49.008,5$ \\
\hline
\end{tabular}

Fonte: Próprio autor (2019).

\subsection{Múltiplos de Lucro}

Ainda que esse múltiplo venha diminuindo nos últimos anos (um bom sinal), ele continua extremamente alto quando comparado com empresas do mesmo setor, como demonstrado anteriormente. Olhando numa janela de 4 anos, o menor múltiplo apresentado pela empresa foi em 2018.

Figura 7: Evolução do Múltiplo de Lucro.

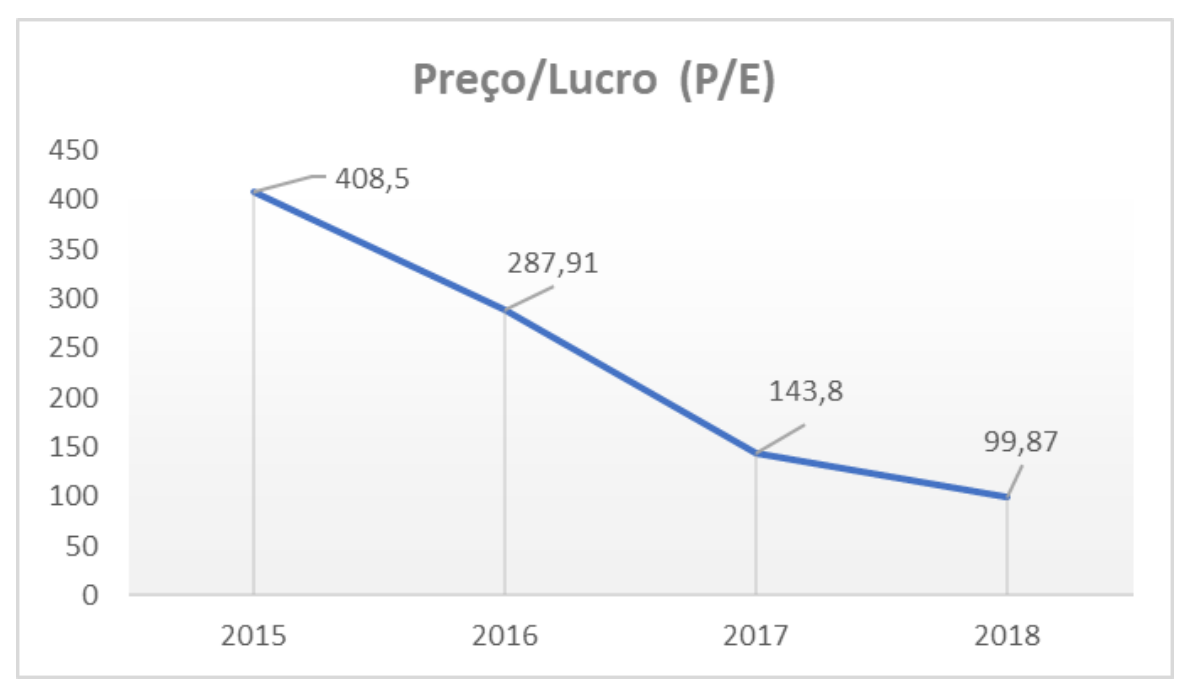

Fonte: Próprio autor (2019). 


\subsection{Múltiplos de Receita}

Esse grupo de múltiplos têm apresentado resultados similares ao longo dos anos analisados, sem nenhum valor muito discrepante do outro. Ainda que em 2016 a Netflix tenha apresentado uma queda no valor desse múltiplo, o mesmo vem aumentando desde então. A linha laranja representa o Enterprise Value da empresa em relação as vendas, enquanto que a linha azul representa seu valor de mercado.

Figura 8: Evolução dos múltiplos de receita.

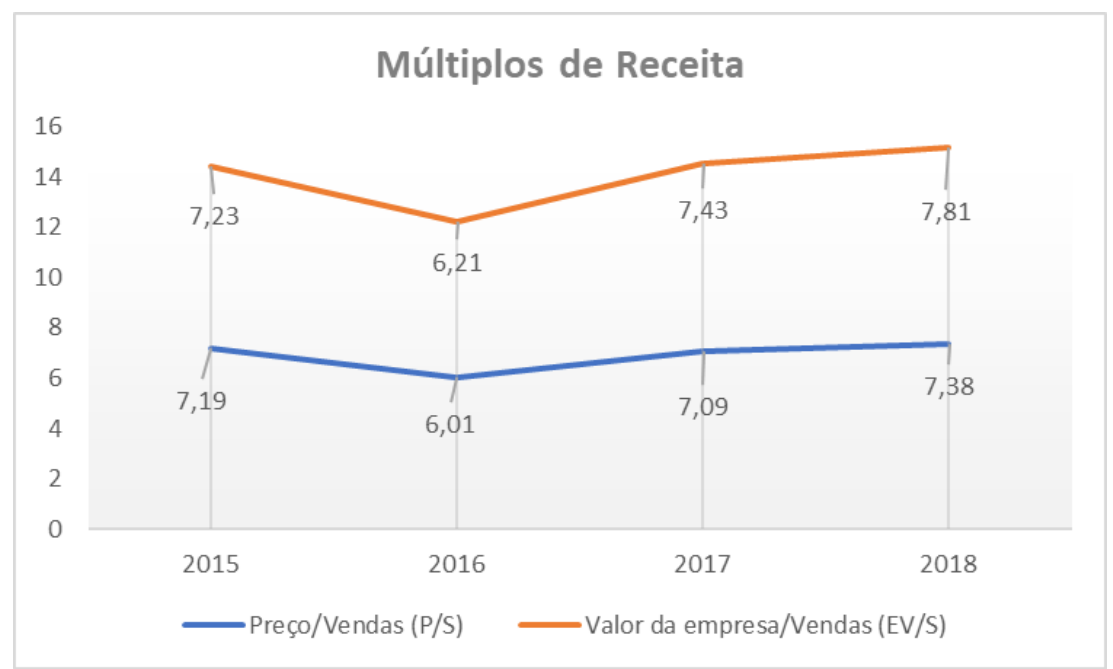

Fonte: Próprio autor (2019).

\subsection{Múltiplos de Patrimônio}

Esse múltiplo vem variando bastante ao longo dos anos. O maior resultado apresentado foi em 2017, sendo $17 \%$ maior do valor de 2016 - o menor dentre os anos estudados. 
Figura 9: Evolução do Múltiplo de Patrimônio Líquido.

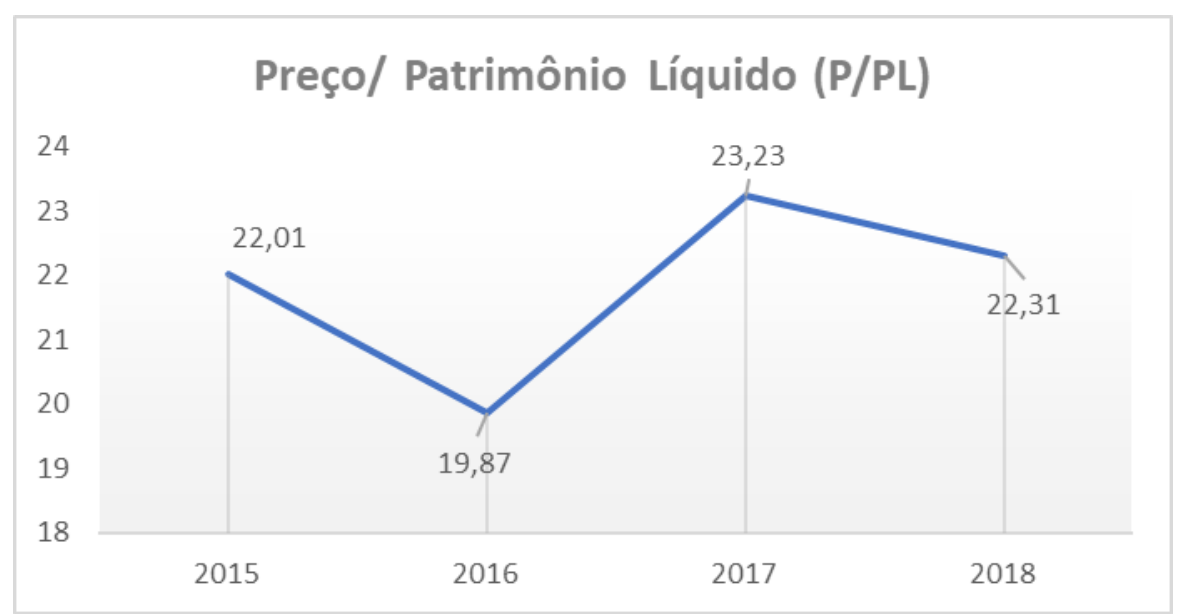

Fonte: Próprio autor (2019).

Assim como o múltiplo de lucro, P/L, o EV/EBITDA vem demonstrando queda desde 2015, apresentando seu menor valor em 2018. Por mais que isso seja um sinal positivo, esse múltiplo permanece bem acima dos apresentados por empresas da mesma indústria.

Figura 10: Evolução do múltiplo de EBITDA

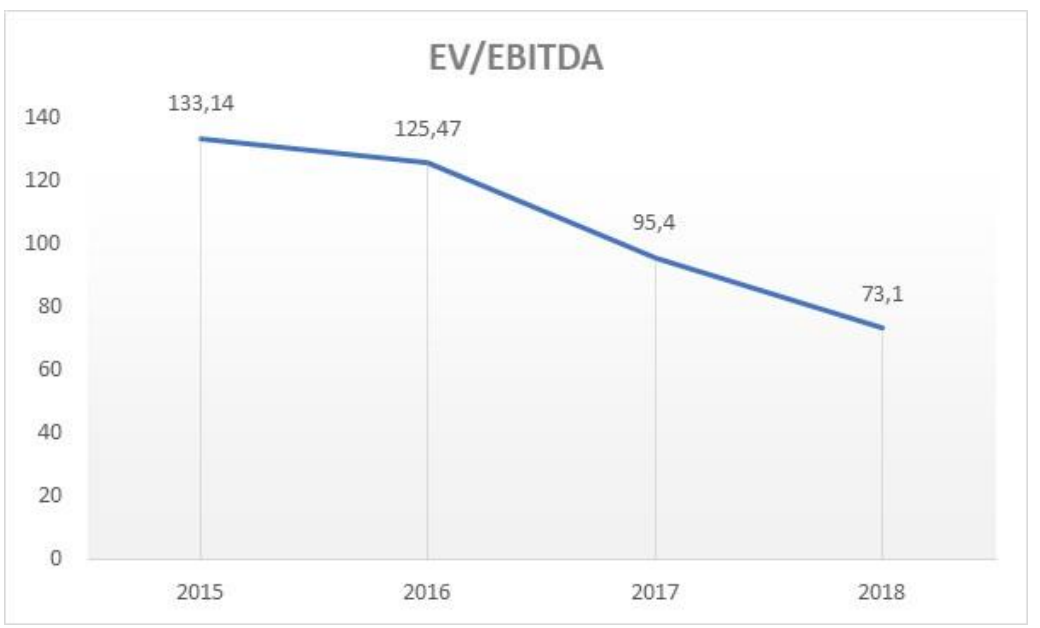

Fonte: Próprio autor (2019). 


\section{Conclusão}

Este trabalho teve como principal objetivo definir, através de diferentes análises, se a Netflix está avaliada acima ou abaixo do que seu preço de mercado. No caso de um cenário em que a empresa estivesse subvalorizada e com potencial de crescimento, a recomendação de investimento seria de compra. Caso contrário, a recomendação seria a de não investir.

Em primeiro plano realizou-se uma análise do mercado de streaming, levando em conta a evolução do mercado, principais players, ameaças e oportunidades. Num ambiente tão dinâmico quanto o de mídia, parece cada vez mais que aquele que produz o melhor conteúdo é quem consegue a parcela na carteira do consumidor, que é limitada. Dado o modelo de negócio da Netflix de produzir uma quantidade imensa de conteúdo com pouca qualidade, fica difícil de enxergar algum momento em que seu fluxo de caixa se tornará positivo, dado que o investimento em produção de conteúdo tende a crescer a cada ano.

Ainda que o método mais utilizado para realizar a valuation de uma empresa seja pelo fluxo de caixa descontado, isso não foi possível nesse estudo dado que a empresa apresenta fluxos negativos. Desse modo, para realizar a avaliação da empresa, levaram-se em conta duas abordagens: a avaliação baseada nos usuários da plataforma (novos e existentes) e a avaliação relativa por múltiplos.

A avaliação baseada por usuários foi dividida em três partes. A primeira parte consistiu em calcular o valor de usuários existentes, o que permitiu calcular a segunda parte: valor dos novos usuários. Por fim, calculou-se os custos corporativos da empresa. Isso permitiu o cálculo do preço justo por ação. O resultado de USD 246,18 foi abaixo da precificação da empresa no mercado de USD 267,66. Isso significa que baseado dos seus resultados, a empresa encontra-se supervalorizada, não sendo recomendável a compra do seu papel.

O segundo método utilizado foi a avaliação por múltiplos, que foi dividido em duas partes: análise comparativa dos múltiplos da Netflix com os de empresas de seu peer group, e também uma análise da evolução dos múltiplos da Netflix ao 
longo de 4 anos (2015 a 2018). Percebe-se que por mais que a empresa tenha demonstrado alguns múltiplos melhores ao longo dos anos, ela permanece com coeficientes muito altos em relação aos seus competidores.

Sem dúvida nenhuma a Netflix é uma gigante que revolucionou o mercado e mudou as preferências do consumidor. No entanto, ao calcular seu preço justo de ação e ao compará-la com empresas do mesmo setor, pode concluir que a empresa está avaliada acima do seu preço real, portanto, não é recomendada uma compra do papel da empresa. Vale ressaltar que a análise feita levou em conta indicadores bastante conservadores, como por exemplo a probabilidade de renovação do serviço de 90\%, que foi a taxa ocorrida pela empresa de 2017 a 2018.

Fora a análise quantitativa, foi realizada também uma análise qualitativa em que se levou em conta o ambiente externo da empresa. Enquanto a Netflix navegava um mar azul em termos de poucos competidores, hoje o mercado de streaming está saturado e conta com a presença de gigantes do entretenimento, mudando de forma significativa o futuro da empresa.

Diante dos pontos mencionados e do estudo realizado, concluiu-se, portanto, que a Netflix está precificada no mercado acima do que ela realmente vale, não sendo recomendada a compra do papel. 


\section{Referências Bibliográficas}

ASSAF, Alexandre. Finanças Corporativas e Valor. São Paulo: Atlas, 2014.

BAINES, Wesley. Beliefnet. How Netflix Changed Entertainment. Disponível em: 〈https://bit.ly/2vknHJj>. Acesso em: 19 mar. 2019.

BLOOMBERG L.P. NFLX Inc. Terminal da Bloomberg. Acesso em: 25 mai. 2019.

CHONG, Celena. Business Insider. Blockbuster's CEO once passed up a Chance to buy Netflix for only $\mathbf{\$ 5 0}$ million. Disponível em:

$<$ https://www.businessinsider.com/blockbuster-ceo-passed-up-chance-to-buynetflix-for-50-million-2015-7>. Acesso em: 22 out. 2018.

DAMODARAN, Aswath. Avaliação de Investimentos. São Paulo: Qualitymark, 1999.

DAMODARAN, Aswath. Como Avaliar Empresas e Escolher as Melhores Ações. Rio de Janeiro: LTC, 2012.

DAMODARAN, Aswath. Musings on Markets. Stream On: An IPO Valuation of Spotify! Disponível em:

$<$ http://aswathdamodaran.blogspot.com/2018/03/stream-on-ipo-valuation-ofspotify.html>. Acesso em: 10 out. 2018.

DAMODARAN, Aswath. Musings on Markets. Netflix: The Future of Entertainment or House of Cards? Disponível em:

$<$ http://aswathdamodaran.blogspot.com/2018/04/netflix-future-of-entertainmentor.html>. Acesso em: 19 mar. 2019.

FORTUNA, Eduardo. Mercado Financeiro. 21 a ed. Rio de Janeiro: Qualitymark, 2017.

HE: BLOG. Conteúdo para solucionar desafios digitais. A Indústria do Entretenimento: humanização por meio da tecnologia. Disponível em:

$<$ https://helabs.com/blog/a-industria-do-entretenimento-humanizacao-por-meioda-tecnologia/>. Acesso em: 09 out. 2018.

HARGRAVE, Marshall. Investopedia. Price-to-Sales Ratio. Disponível em: <https://www.investopedia.com/terms/p/price-to-salesratio.asp>. Acesso em: 23 mai. 2019. 
HULU. Press Release. Hulu tops 25 million total subscribers in 2018. Disponível em: <https://www.hulu.com/press/hulu-tops-25-million-total-subscribers-in2018/>. Acesso em: 10 mai. 2019.

MARTELANC, R.; PASIN, R. CALVACANTE, F. Avaliação de empresas. São Paulo: Pearson, 2005.

MAVERICK, J. B. Investopedia. What is considered a healthy EV/EBITDA? Disponível em: <https://www.investopedia.com/ask/answers/072715/whatconsidered-healthy-evebitda.asp>. Acesso em: 23 mai. 2019.

MCBRIDE, Stephen. Forbes. Netflix Has 175 Days Left to Pull Off a Miracle... Or it's all Over. Disponível em:

$<$ https://www.forbes.com/sites/stephenmcbride1/2019/05/21/netflix-has-175-

days-left-to-pull-off-a-miracle-or-its-all-over/\#d84a6c375c40>. Acesso em: 25 mai. 2019.

ROSS, S. A. et al. Fundamentals of Corporate Finance. Australia: McGraw-Hill Education, 2013.

SINGH, Manish. CNBC. Netflix and Amazon are struggling to win over the world's second-largest internet Market. Disponível em:

$<$ https://www.cnbc.com/2018/07/05/netflix-and-amazon-are-struggling-to-winover-indian-viewers.html>. Acesso em 10 mai. 2019.

SRIVASTAVA, Spriha. The US Bond Yield Curve Has Inverted. CNBC. Disponível em: https://www.cnbc.com/2019/03/25/the-us-bond-yield-curve-hasinverted-heres-what-it-means.html>. Acesso em: 10 mai. 2019.

STATISTA. Cord Cutting in the US. Disponível em:

$<<$ https://www.statista.com/study/53326/cord-cutting-in-the-us/>. Acesso em: 01 abr. 2019

STATISTA. Video-on-Demand Worldwide. Disponível em:

<https://www.statista.com/outlook/201/100/video-on-demand/worldwide>.

Acesso em: 19 abr. 2019.

YAHOO Finance. Netflix, Inc. (NFLX). Disponível em:

<https://finance.yahoo.com/quote/NFLX/>. Acesso em: 01 mai. 2019. 


\section{Apêndice}

Apêndice 1: Valor de usuários existentes

\begin{tabular}{|c|c|c|c|c|c|c|c|c|c|c|c|c|}
\hline Anos & & 0 & 1 & 2 & 3 & 4 & 5 & 6 & 7 & 8 & 9 & 10 \\
\hline & & & 1 & 1 & 1 & 1 & 1 & 1 & 1 & 1 & 1 & 1 \\
\hline Probabilidade de Renovação & & 1,0000 & 0,9000 & 0,8100 & 0,7290 & 0,6561 & 0,5905 & 0,5314 & 0,4783 & 0,4305 & 0,3874 & 0,3487 \\
\hline Lucro/Usuário & $\$$ & $124,56 \$$ & $\$ 137,02$ & $\$ \quad 150,72$ & $\$ 165,79$ & \$ 182,37 & 200,61 & $\$ 220,67$ & $\$ 242,73$ & $\$ 267,01$ & $\$ 293,71$ & 323,08 \\
\hline Custo/Usuário & $\$$ & \begin{tabular}{ll|l}
15,39 & $\$$
\end{tabular} & 15,88 & 16,43 & $\$ \quad 17,03$ & $\$ \quad 17,69$ & 18,42 & 19,22 & $\$ \quad 20,10$ & $\$ \quad 21,07$ & 22,14 & 23,31 \\
\hline EBITDA & $\$$ & 109,17 & $\$ 121,13$ & $\$ \quad 134,29$ & $\$ 148,76$ & $\$ 164,68$ & 182,18 & $\$ 201,44$ & $\$ 222,63$ & $\$ 245,93$ & $\$ 271,57$ & 299,77 \\
\hline Taxa & & $25,00 \%$ & $25,00 \%$ & $25,00 \%$ & $25,00 \%$ & $25,00 \%$ & $25,00 \%$ & $25,00 \%$ & $25,00 \%$ & $25,00 \%$ & $25,00 \%$ & $25,00 \%$ \\
\hline Lucro (perda) operacional por usuário & & $\$ 81,88$ & $\$ 81,76$ & $\$ 81,58$ & $\$ 81,33$ & $\$ 81,03$ & $\$ 80,68$ & $\$ 80,29$ & $\$ 79,86$ & $\$ 79,40$ & $\$ 78,91$ & $\$ 78,39$ \\
\hline Valor Presente & & & $\$ 71,94$ & $\$ 63,16$ & $\$ 55,40$ & $\$ 48,57$ & $\$ 42,55$ & $\$ 37,25$ & $\$ 32,60$ & $\$ 28,52$ & $\$ 24,94$ & $\$ 21,80$ \\
\hline Valor por usuário & $\$$ & 426,72 & & & & & & & & & & \\
\hline Quantidade de usuários (milhōes) & & 148,37 & & & & & & & & & & \\
\hline Valor de Usuários Existentes (milhões) & & $3.313,18$ & & & & & & & & & & \\
\hline
\end{tabular}

Apêndice 2: Valor de novos usuários

Valor de usuário novo

\begin{tabular}{|l|r|}
\hline Custo de adquirir novos usuários & $\$ 111,39$ \\
\hline Lucro por usuário & \\
\hline
\end{tabular}

\begin{tabular}{|l|c|c|c|c|c|c|c|c|c|c|c|}
\hline & Base Year & 1 & 2 & 3 & 4 & 5 & 6 & 7 & 8 & 9 & 10 \\
\hline Total de Usuários & 148,37 & 170,63 & 196,22 & 225,65 & 259,50 & 298,43 & 328,27 & 361,09 & 397,20 & 436,92 & 480,62 \\
\hline Usuários Novos & - & 37,09 & 42,66 & 49,05 & 56,41 & 64,88 & 59,69 & 65,65 & 72,22 & 79,44 & 87,38 \\
\hline Valor por usuário & $\$ 315,34$ & $\$ 346,87$ & $\$ 381,56$ & $\$ 419,72$ & $\$ 461,69$ & $\$ 507,86$ & $\$ 558,64$ & $\$ 614,51$ & $\$ 675,96$ & $\$ 743,55$ & $\$ 817,91$ \\
\hline Valor adicionado por novos usuário & & $\$ 12,866,40$ & $\$ 16.275,99$ & $\$ 20.589,13$ & $\$ 26,045,25$ & $\$ 32,947,24$ & $\$ 33.342,61$ & $\$ 40.344,56$ & $\$ 48.816,92$ & $\$ 59.068,47$ & $\$ 71.472,85$ \\
\hline Valor Terminal (novos usuários) & & & & & & & & & & & $\$ 103.218,81$ \\
\hline PV Valor de novos usuários & & $\$ 11.320,70$ & $\$ 12.600,27$ & $\$ 14.024,47$ & $\$ 15.609,65$ & $\$ 17.374,00$ & $\$ 15.470,22$ & $\$ 16.470,17$ & $\$ 17.534,75$ & $\$ 18.668,15$ & $\$ 48.577,35$ \\
\hline
\end{tabular}

\begin{tabular}{|l|l|}
\hline Valor adicionado novos usuários (milhões) $\$ 187.649,73$ \\
\cline { 2 - 2 }
\end{tabular}

\section{Apêndice 3: Custos corporativos}

\section{Custos Corporativos}

Tecnologia \& Desenvolvimento

Custos de Conteúdo

Custos corporativos depois da taxa

Valor Terminal (Custo corporativo)

PV Custo Corporativo

Total Custos Corporativos

\begin{tabular}{|r|r|r|r|r|r|r|r|r|r|r|}
\multicolumn{1}{c}{ Base Year } & \multicolumn{1}{c}{1} & \multicolumn{1}{c}{3} & \multicolumn{1}{c}{4} & \multicolumn{1}{c}{5} & \multicolumn{1}{c}{6} & \multicolumn{1}{c}{8} & \multicolumn{1}{c|}{9} & 10 \\
\hline$\$ 1.221,00$ & $\$ 1.282,05$ & $\$ 1.346,15$ & $\$ 1.413,46$ & $\$ 1.484,13$ & $\$ 1.558,34$ & $\$ 1.636,26$ & $\$ 1.718,07$ & $\$ 1.803,97$ & $\$ 1.894,17$ & $\$ 1.988,88$ \\
\hline$\$ 5.524,70$ & $\$ 5.718,07$ & $\$ 5.918,20$ & $\$ 6.125,33$ & $\$ 6.339,72$ & $\$ 6.561,61$ & $\$ 6.791,27$ & $\$ 7.028,96$ & $\$ 7.274,98$ & $\$ 7.529,60$ & $\$ 7.793,14$ \\
\hline & $\$ 5.250,09$ & $\$ 5.448,26$ & $\$ 5.654,10$ & $\$ 5.867,89$ & $\$ 6.089,96$ & $\$ 6.320,64$ & $\$ 6.560,27$ & $\$ 6.809,21$ & $\$ 7.067,83$ & $\$ 7.336,51$ \\
\hline & & & & & & & & & & $\mathrm{R} \$ 67.091,62$ \\
\hline & $\$ 5.966,92$ & $\$ 7.037,62$ & $\$ 8.300,70$ & $\$ 9.790,78$ & $\$ 11.548,72$ & $\$ 13.622,74$ & $\$ 16.069,74$ & $\$ 18.956,91$ & $\$ 22.363,54$ & $\$ 20.696,59$ \\
\hline
\end{tabular}




\section{Anexo}

Anexo 1: Balanço Patrimonial da Netflix.

\begin{tabular}{|c|c|c|}
\hline \multicolumn{3}{|c|}{ Netflix Inc (NFLX US) } \\
\hline In Millions of USD except Per Share & FY 2017 & FY 2018 \\
\hline 12 Months Ending & $12 / 31 / 2017$ & $12 / 31 / 2018$ \\
\hline \multicolumn{3}{|l|}{ Balance Sheet } \\
\hline \multicolumn{3}{|l|}{ Current Assets } \\
\hline Cash and Equivalents & $2.822,8$ & $3.794,5$ \\
\hline Prepaid Expenses (Short-Term) & - & - \\
\hline Other Current Assets & $4.847,2$ & $5.899,7$ \\
\hline Short-Term Investments & - & - \\
\hline Total Current Assets & $7.670,0$ & $9.694,1$ \\
\hline \multicolumn{3}{|l|}{ Noncurrent Assets } \\
\hline Property Plant \& Equipment - Net & 319,4 & 418,3 \\
\hline Other Noncurrent Assets & 652,3 & 901,0 \\
\hline Program/Broadcast Rights (Long-term) & $10.371,1$ & $14.961,0$ \\
\hline Total Assets & $19.012,7$ & $25.974,4$ \\
\hline \multicolumn{3}{|l|}{ Current Liabilities } \\
\hline Accounts Payable - Trade & 359,6 & 563,0 \\
\hline Accrued Expenses & 315,1 & 477,4 \\
\hline Deferred/Unearned Revenue (Short-Term) & 618,6 & 760,9 \\
\hline Other Current Liabilities & $4.173,0$ & $4.686,0$ \\
\hline Total Current Liabilities & $5.466,3$ & $6.487,3$ \\
\hline \multicolumn{3}{|l|}{ Non Current Liabilities } \\
\hline Long Term Debt & $6.499,4$ & $10.360,1$ \\
\hline Other Noncurrent Liabilities & $3.465,0$ & $3.888,3$ \\
\hline Total Liabilities & $15.430,8$ & $20.735,6$ \\
\hline \multicolumn{3}{|l|}{ Stockholder Equity } \\
\hline Preferred Stock & 0,0 & 0,0 \\
\hline \multicolumn{3}{|l|}{ Additional Paid In Capital } \\
\hline Accumulated Other Comprehensive Income & $-20,6$ & $-19,6$ \\
\hline Retained Earnings (Accumulated Deficit) & $1.731,1$ & $2.942,4$ \\
\hline Shares Outstanding & 433,4 & 436,6 \\
\hline Par Value & 0,00 & 0,00 \\
\hline Common Stock \& APIC & $1.871,4$ & $2.316,0$ \\
\hline Shares Issued & 433,4 & 436,6 \\
\hline Total Shareholders Equity & $3.582,0$ & $5.238,8$ \\
\hline Shares Authorized & $4.990,0$ & $4.990,0$ \\
\hline Preferred Stock Shares Outstanding & - & - \\
\hline Total Liabilities and Shareholders Equity & $19.012,7$ & $25.974,4$ \\
\hline
\end{tabular}

Fonte: Bloomberg, 2019. 